\title{
On the Leading Patterns of Northern Hemisphere Sea Level Pressure Variability*
}

\author{
BRIAN V. SMOLIAK ${ }^{+}$AND JOHN M. WALLACE \\ Department of Atmospheric Sciences, University of Washington, Seattle, Washington
}

(Manuscript received 12 December 2014, in final form 13 May 2015)

\begin{abstract}
The leading patterns of variability of the monthly mean Northern Hemisphere (NH) sea level pressure (SLP) field, as derived from empirical orthogonal teleconnection (EOT) analysis of a 93-yr (1920-2012) record of NOAA-CIRES 20th Century Reanalyses, are presented and discussed, with emphasis on wintertime patterns. The analysis yields nine or more highly reproducible wintertime hemispheric EOTs, the first six of which closely resemble EOF1 or EOF2 in their respective sectors of the hemisphere. Collectively, the first nine wintertime patterns account for $70 \%$ of the variance of NH SLP, $40 \%$ of the variance of NH surface air temperature (SAT), and $52 \%$ of the variance of the time series of NH-mean SAT poleward of $20^{\circ} \mathrm{N}$. Wintertime EOT1 corresponds to the NH annular mode (NAM) and EOT2 corresponds to the SLP expression of the Pacific-North America pattern. The remaining wintertime EOT patterns are monopoles arranged like the links of a chain wrapped around the primary center of action of the annular mode. The NH summertime and Southern Hemisphere patterns are arranged in a similar manner. The continental $\mathrm{NH}$ wintertime patterns exhibit strong temperature anomalies of reversed polarity to their respective SLP monopoles. The interannual variability of wintertime EOTs 3-9 and summertime EOTs $2-9$ is dominated by sampling fluctuations. Over the $93-y r$ record, the more prominent continental wintertime patterns exhibit weak trends toward falling SLP and rising SAT, particularly over Russia and Alaska. The interpretation of shorter-term trends is more ambiguous.
\end{abstract}

\section{Introduction}

Northern Hemisphere (NH) wintertime climate variability exhibits preferred spatial patterns of sea level pressure (SLP) and geopotential height. These so-called teleconnection patterns play an important role in organizing the variability on the month-to-month time scale and there are indications that they become increasingly prominent at longer and longer time scales (Quadrelli and Wallace 2004; Dommenget and Latif 2008). The study of atmospheric teleconnections has progressed from its origins in heuristic analyses of station data beginning in the late nineteenth century (Teisserenc de Bort 1883; Hildebrandsson 1897; Exner 1913; Walker 1924; Defant

\footnotetext{
* Supplemental information related to this paper is available at the Journals Online website: http://dx.doi.org/10.1175/JAS-D-14-0371.s1.

${ }^{+}$Current affiliation: The Climate Corporation, Seattle, Washington.

Corresponding author address: Brian V. Smoliak, The Climate Corporation, 710 2nd Ave., Suite 1100, Seattle, WA 98104.

E-mail: bsmoliak@climate.com
}

1924; Ångström 1935) to contemporary objective analyses of globally gridded data, the latter yielding a multiplicity of patterns (Wallace and Gutzler 1981; Barnston and Livezey 1987; Panagiotopoulos et al. 2002).

Quadrelli and Wallace (2004, hereafter QW) showed that the leading modes of low-frequency variability of the Northern Hemisphere wintertime circulation are clearly revealed by linear combinations of the two leading empirical orthogonal functions (EOFs) of the SLP field, which together account for $37 \%$ of the variance of monthly mean data poleward of $20^{\circ} \mathrm{N}$. A limitation of their analysis is that these two patterns do not explain much of the variability over large regions of the $\mathrm{NH}$, such as the Eurasian continent and the Arctic. This study seeks to provide a parsimonious yet dynamically relevant characterization of $\mathrm{NH}$ wintertime variability that can be extended to include additional patterns.

As in QW, the definition of the patterns is based on the SLP field and the corresponding upper-air patterns are derived by linear regression. The patterns based on the SLP field tend to be more monopolar and regionalized than patterns based on the geopotential height field aloft. The simpler patterns are amenable to more straightforward description and classification. It 
remains to be seen whether the dynamical interpretation will be more straightforward as well.

In this study we consider the results of three different analysis techniques: EOF analysis, rotated EOF (REOF) analysis, and empirical orthogonal teleconnection (EOT) analysis. Of the three methods, EOF analysis is-by construction-the most efficient at explaining the largest fraction of variability with the fewest modes, but the higher modes tend to be more spatially complex and more fragile with respect to sampling variability (Richman 1986; Cheng and Dunkerton 1995). Rotation alleviates these problems, at the price of some loss of efficiency in explaining variance. Most published studies are based on varimax rotation of the principal component time series, which yields mutually orthogonal "expansion coefficient" time series but spatially correlated maps as explained in Horel (1981) and Kushnir and Wallace (1989). The rotation is performed in a truncated EOF space whose dimension needs to be prescribed by the user: the larger the space, the simpler (more monopolar) and more robust the patterns, but there exists a wide range of truncations for which the results tend to be similar. The higher-order rotated EOFs tend to be much more robust with respect to sampling variability than conventional EOFs (Cheng et al. 1995). EOT analysis (Van den Dool et al. 2000) is an alternative method for obtaining simple, regionalized patterns based on one-point covariance maps. As in rotated EOF analysis, EOT analysis may be configured such that either the spatial patterns or the corresponding expansion coefficient time series are mutually orthogonal.

In defining higher-order hemispheric teleconnection patterns, the analyst is faced with a choice of how simple the modes should be (spatially). The emphasis in this study is on obtaining simple patterns, so we use a relatively high-dimensional phase space for the rotated EOF analysis and we rely heavily on EOT analysis. We will demonstrate the robustness of our patterns by cross validation and showing the similarity of the EOTs, rotated EOFs, and sectoral EOFs.

Section 2 describes the data and summarizes the methodology used in this paper. Section 3 describes the leading patterns obtained by applying different analysis techniques to the NH wintertime [December-March (DJFM)] SLP field. Section 4 presents a brief summary of the modes in NH summer [June-September (JJAS)] and section 5 offers a discussion and dynamical interpretation of the patterns, including a comparison with the leading EOTs of the Southern Hemisphere (SH) extratropical circulation. Monthly time series of the $\mathrm{NH}$ pattern indices are provided in digital form in the supplemental material.

\section{Data and methodology}

In this study we make use of the SLP field and the 500-hPa height field from the NOAA-CIRES 20th Century Reanalysis (20CR), version 2 (Compo et al. 2011), obtained from the NOAA ESRL PSD, Boulder, Colorado. On the basis of gridpoint-by-gridpoint correlations, Compo et al. (2011) showed that the 20CR geopotential height field matches well with other reanalyses, particularly over the extratropical NH - the region that is the focus of this study. The 20CR dataset dates back to 1871. Based on performance characteristics of the 20CR in Compo et al. (2011), which show a sharp improvement after the end of World War I in the NH and after the end of World War II in the SH, we choose the 1919/20 boreal winter as the starting point for our NH analysis and the 1944/45 austral summer as the starting point for our SH analysis. We have not examined data in the respective hemispheres prior to those dates.

To investigate surface air temperature (SAT) patterns associated with the leading patterns of $\mathrm{NH}$ wintertime SLP variability, we supplemented the 20CR atmospheric fields with the SAT field (land only) from two globally gridded observational datasets: the high-resolution $\left(0.5^{\circ}\right.$ latitude by $0.5^{\circ}$ longitude) CRU TS 3.22 dataset (Harris et al. 2014) and the coarser ( $5^{\circ}$ latitude by $5^{\circ}$ longitude) Global Historical Climatology Network (GHCN), version 3 (Lawrimore et al. 2011). For a given variable, monthly mean anomaly fields were obtained by subtracting the climatological means for each calendar month from the monthly time series at each grid point. The SLP anomalies are area weighted by the square root of the cosine of latitude, and analyses are carried out for the domain poleward of $20^{\circ} \mathrm{N}$ for the $93-\mathrm{yr}$ period of record from November 1919 through October 2012. Our primary results are based on an extended winter season, December-March (e.g., December 1919-March 1920 is labeled as "the 1920 winter") and an extended summer season, June-September.

EOF analysis was performed both on the hemispheric SLP field and on the SLP field defined by various $120^{\circ}$ longitude sectors extending from $20^{\circ}$ to $90^{\circ} \mathrm{N}$. Rotated EOFs were obtained using varimax rotation (Kaiser 1958). Rotated EOFs and their corresponding rotated principal components are not necessarily mutually orthogonal (Mestas-Nuñez 2000). To obtain mutually orthogonal rotated principal components, we scaled the length of each eigenvector by the square root of its corresponding eigenvalue, as described by Wilks (2011). This rotation was performed on the first 30 EOFs of the hemispheric SLP field, which account for $95 \%$ of its variance. The rationale for this is twofold: we want the patterns to be geometrically simple and we want to ensure that the higher-order modes (out to 9) are unaffected by the truncation. 

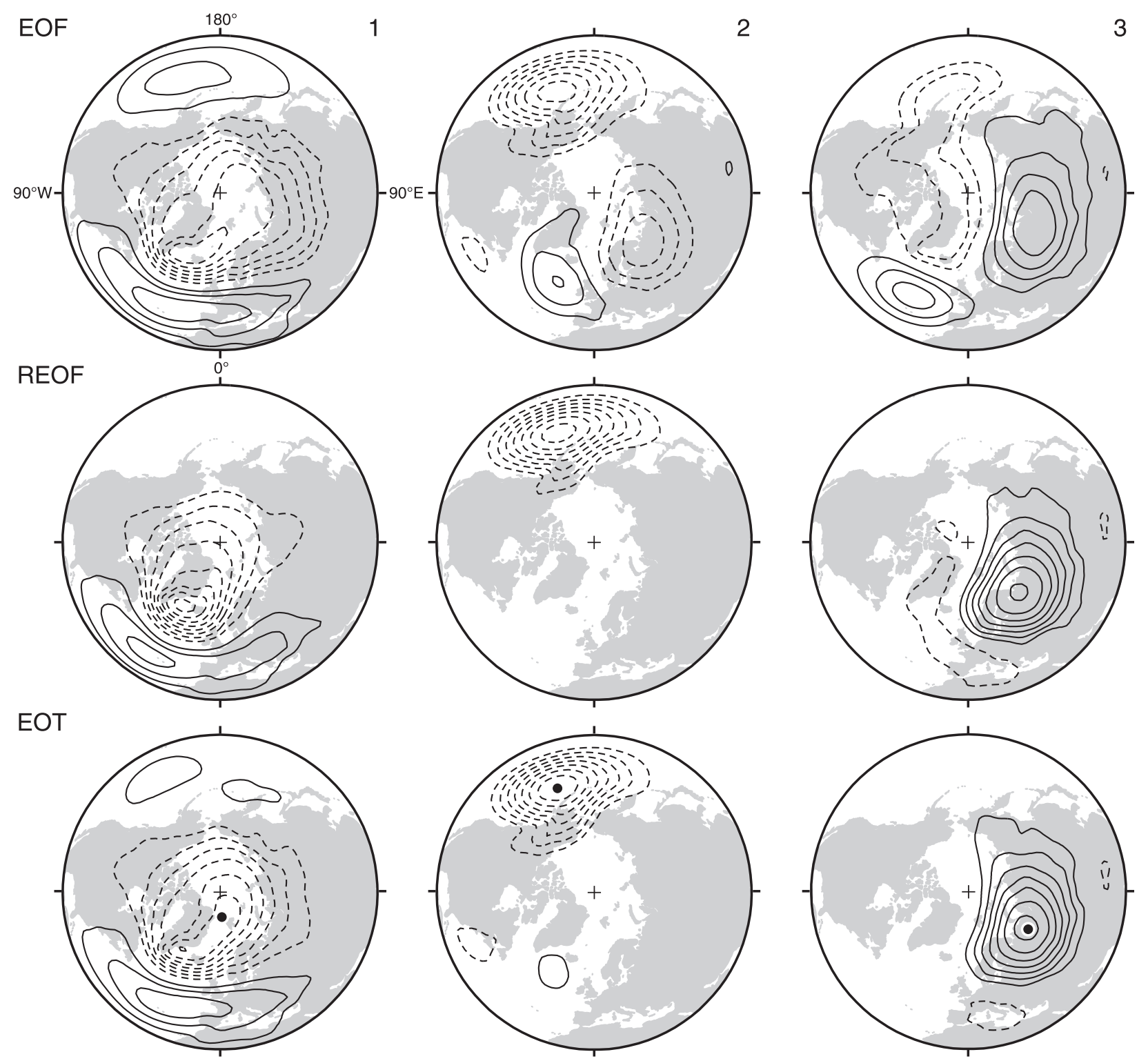

FIG. 1. The leading three patterns of NH wintertime (DJFM) SLP variability, based on a 93-yr (1920-2012) record of SLP anomalies from the 20CR, as identified by (top) EOF analysis, (middle) a varimax rotation of the leading 30 EOFs weighted by the square root of their eigenvalue, and (bottom) EOT analysis, displayed as a regression of local SLP anomalies onto the respective standardized expansion coefficient time series. EOT base points are indicated with black circles. Contour interval is $1 \mathrm{hPa}$ per standard deviation of the corresponding expansion coefficient time series, zero contour is omitted, and negative values are contoured with dashed lines. For visualization purposes, the polarity of the leading two patterns is defined to be consistent with previous papers.

The normal procedure for EOT analysis, as described in Van den Dool et al. (2000), can be summarized as follows. For each grid point, a one-point covariance map is constructed by projecting the Northern Hemisphere SLP field poleward of $20^{\circ} \mathrm{N}$ upon that grid point's SLP time series. The SLP time series for the grid point with the largest area-weighted mean covariance defines EOT1. The spatial pattern for EOT1 is the corresponding one-point regression map. The EOT1 grid point time series is regressed out of the SLP field at each grid point to create a residual field. The preceding steps are repeated on the residual fields to obtain successive EOTs with mutually orthogonal expansion coefficient time series.

\section{Patterns of NH wintertime SLP variability}

The leading three patterns of NH wintertime SLP variability, as determined by EOF, REOF, and EOT 


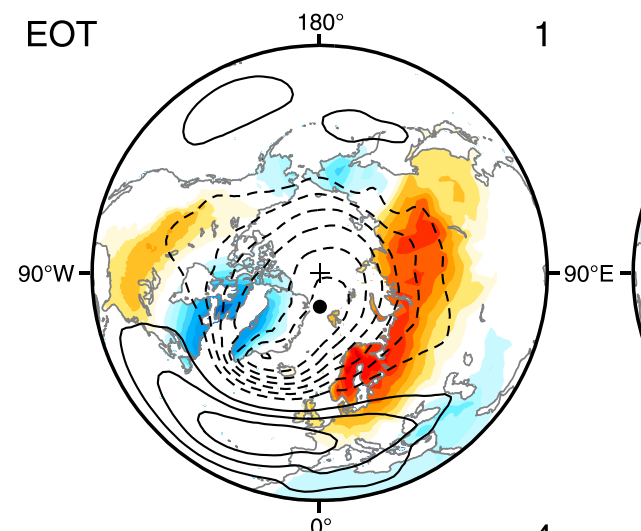

4

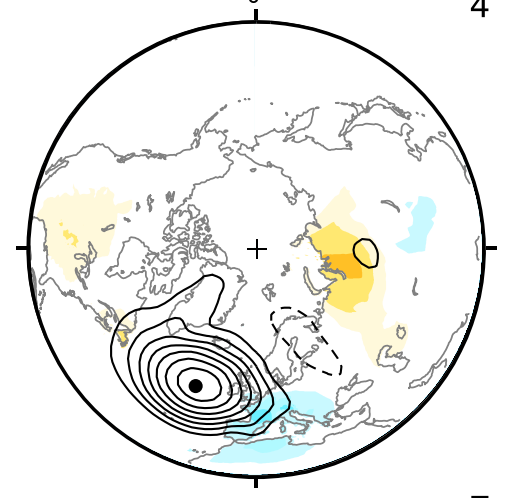

7

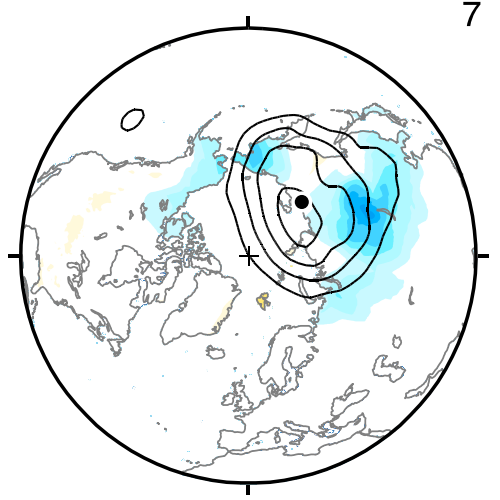

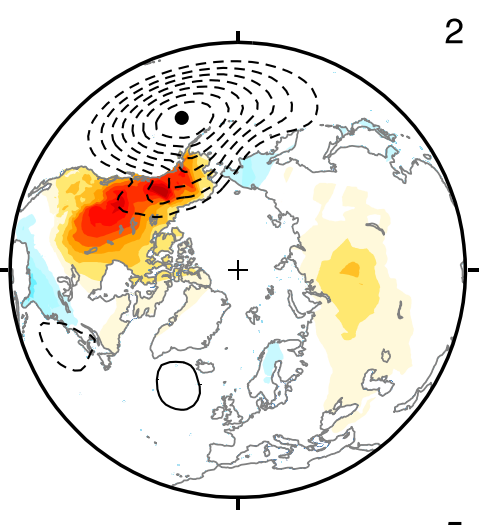
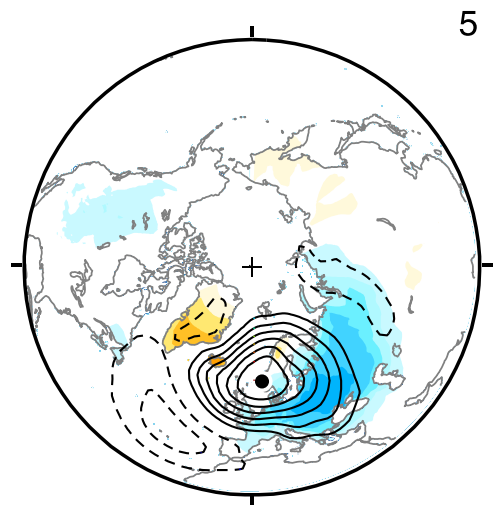

8
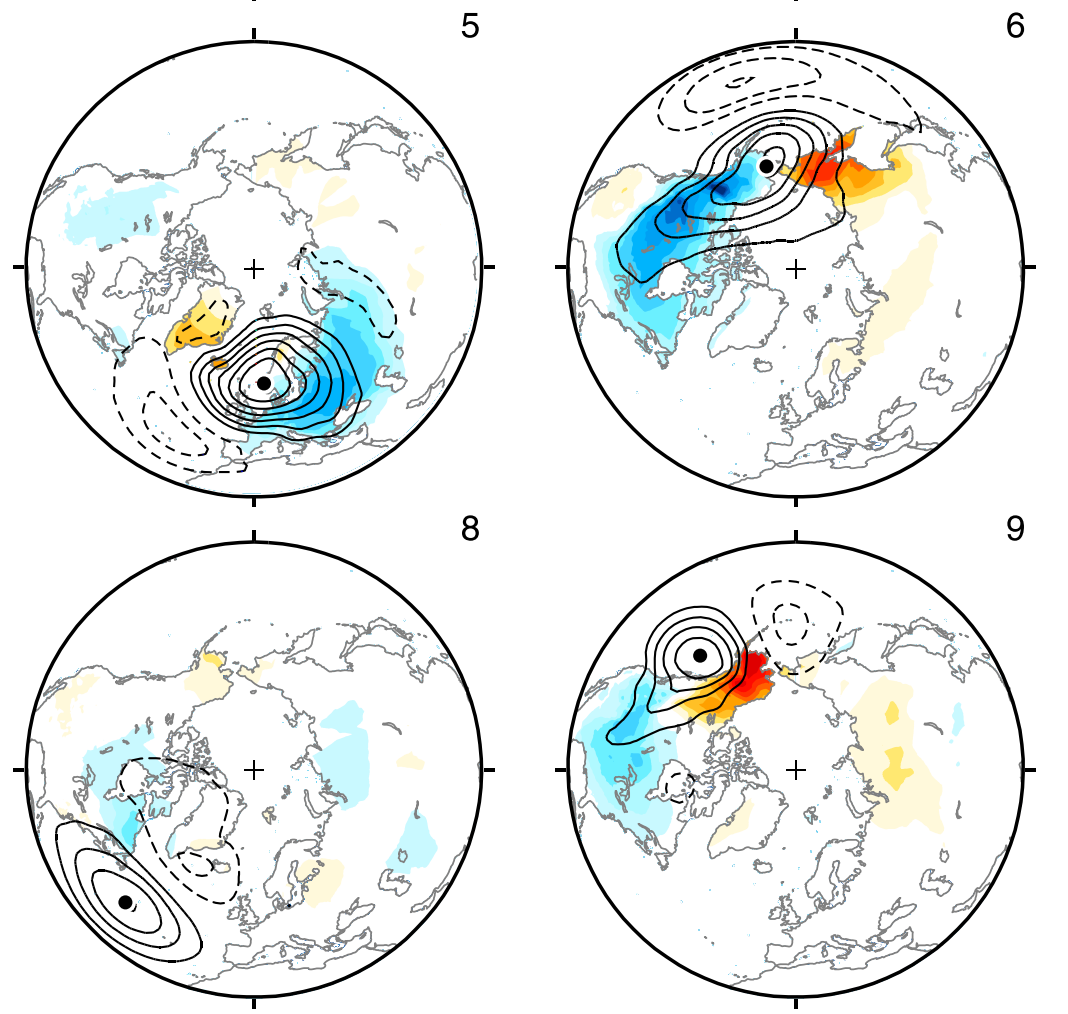

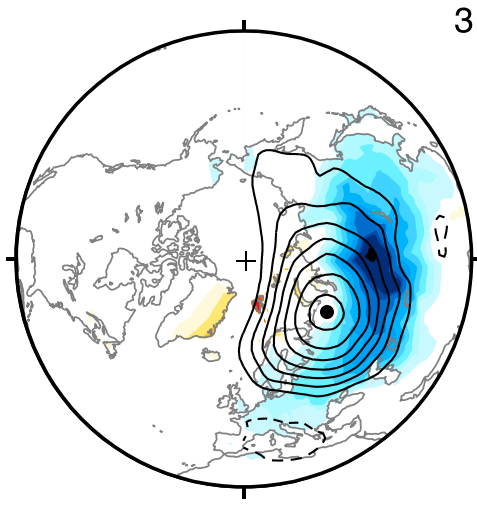

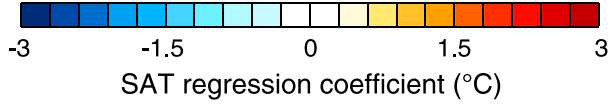

FIG. 2. The leading EOTs of NH wintertime SLP, based on a 93-yr (1920-2012) record of SLP anomalies from the 20CR, displayed as in Fig. 1 (bottom). Regression coefficients of the CRU TS 3.22 SAT field onto the corresponding standardized EOT expansion coefficient time series are shown in colors. Contour interval is $1 \mathrm{hPa}$ per standard deviation of the corresponding expansion coefficient time series, zero contour is omitted, and negative values are dashed. For visualization purposes, the polarity of the leading two patterns is defined to be consistent with previous papers.

analysis, are shown in Fig. 1. The leading mode, EOF1, corresponds to the North Atlantic Oscillation (NAO; Walker and Bliss 1932; van Loon and Rogers 1978; Hurrell 1995), also known as the Northern Hemisphere annular mode (NAM; Thompson and Wallace 2000). It is characterized by a center of action over the Arctic and opposing centers of action over the Atlantic and Pacific around $45^{\circ} \mathrm{N}$. A slightly more Atlantic-centric version of the NAM appears as REOF1 and EOT1. The second mode, EOF2, with its primary center of action in the vicinity of the climatological-mean Aleutian low is the SLP expression of the Pacific-North America (PNA) pattern, as discussed in QW. The patterns for REOF2 and EOT2 are similar, but they place greater emphasis on the primary 
TABLE 1. Statistics derived from the leading nine monthly wintertime (DJFM) EOT expansion coefficient time series: fraction of NH wintertime SLP variance explained (\%), fraction of NH SAT variance explained (\%), fraction of NHSAT (area-average time series, land only, with detrended EOTs) variance explained (\%), linear trend during 1920-2012, ratio of the interannual to the intraseasonal variances, and 1-month-lag autocorrelation. Data from the 20CR. SAT data from CRU TS (NH SAT field) and GHCN (land-only NHSAT areaaverage time series).

\begin{tabular}{|c|c|c|c|c|c|c|}
\hline \multirow[b]{2}{*}{ EOT } & \multicolumn{3}{|c|}{ Variance explained } & \multirow{2}{*}{$\begin{array}{l}\text { Linear trend } \\
(1920-2012)\end{array}$} & \multirow{2}{*}{$\begin{array}{c}\text { Variance } \\
\text { ratio }\end{array}$} & \multirow{2}{*}{$\begin{array}{l}\text { 1-month-lag } \\
\text { autocorrelation }\end{array}$} \\
\hline & NH SLP & NH SAT & NHSAT & & & \\
\hline 1 & 18.5 & 9.4 & 11.3 & 0.13 & 0.67 & 0.33 \\
\hline 2 & 10.8 & 4.4 & 2.7 & 0.39 & 0.77 & 0.33 \\
\hline 3 & 10.8 & 9.2 & 25.5 & -0.77 & 0.38 & 0.16 \\
\hline 4 & 7.4 & 1.1 & 0.1 & 0.58 & 0.32 & 0.01 \\
\hline 5 & 6.6 & 3.2 & 5.0 & -0.11 & 0.39 & 0.07 \\
\hline 6 & 6.0 & 5.4 & 3.7 & -0.48 & 0.37 & 0.10 \\
\hline 7 & 4.1 & 1.9 & 1.7 & -0.41 & 0.43 & 0.04 \\
\hline 8 & 3.2 & 1.0 & 0.1 & 0.43 & 0.40 & 0.10 \\
\hline 9 & 2.9 & 3.0 & 1.3 & -0.28 & 0.29 & -0.07 \\
\hline
\end{tabular}

center of action. EOF3, with its primary center of action around $80^{\circ} \mathrm{E}$ over the Urals, has received less attention in the literature than the leading two patterns, perhaps out of concern that its structure is more likely to be influenced by orthogonality constraints than the patterns that precede it in the hierarchy. This concern notwithstanding, the similarity between hemispheric EOF3, REOF3, and
EOT3 suggests that the dominant center of action in this mode is of dynamical significance (Smoliak 2009).

Subsequent EOFs of the SLP field exhibit more complex patterns that are difficult to interpret, but the REOFs and EOTs continue to exhibit patterns with a single dominant center of action. Emphasizing these simpler patterns, we will extend the analysis, showing

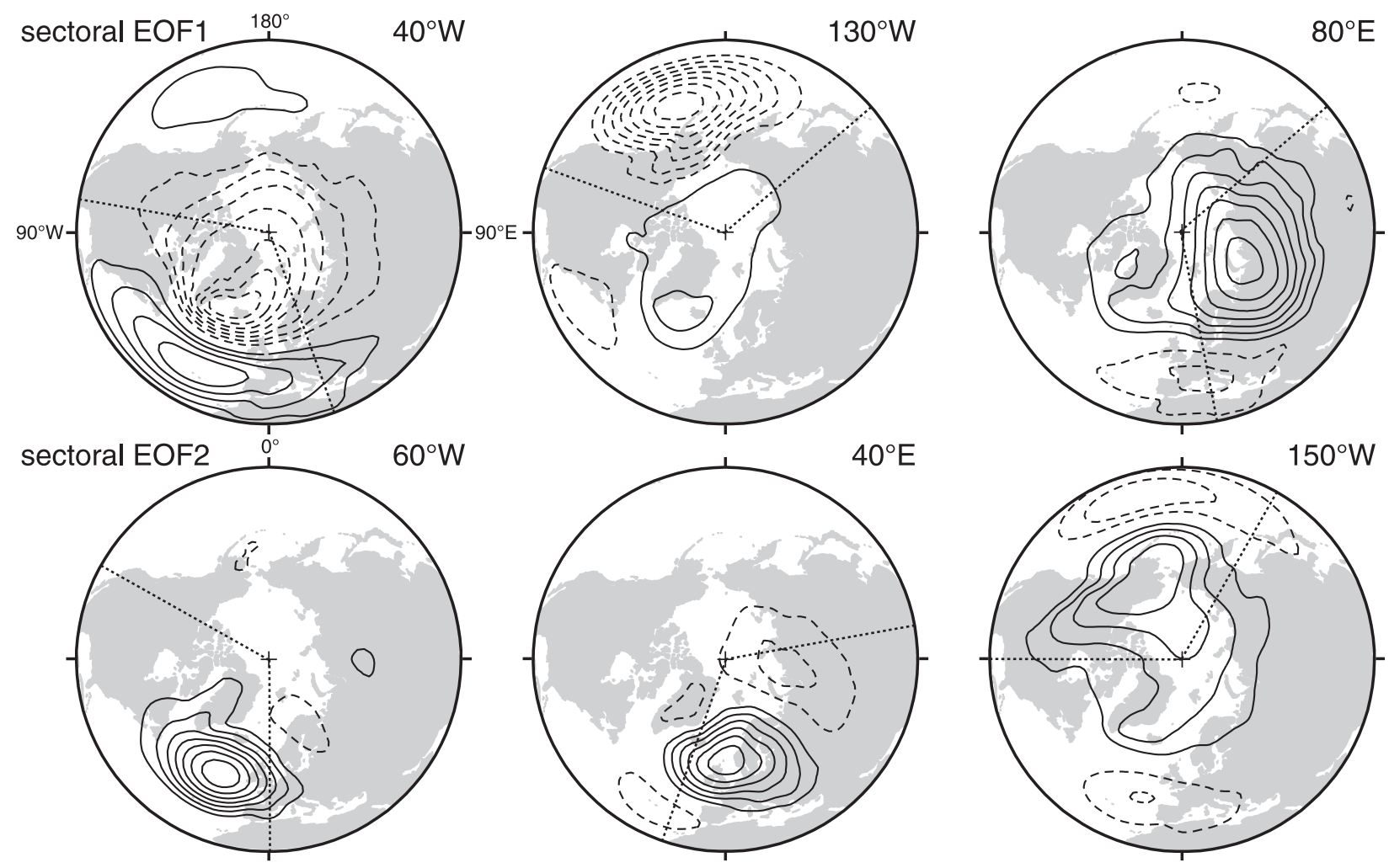

FIG. 3. The leading patterns of NH wintertime SLP variability, as reflected in sectoral (top) EOF1 and (bottom) EOF2 patterns for $120^{\circ}$ sectors. Contouring conventions as in Fig. 1. The central longitude of the sectors is indicated to the upper right of each map. 

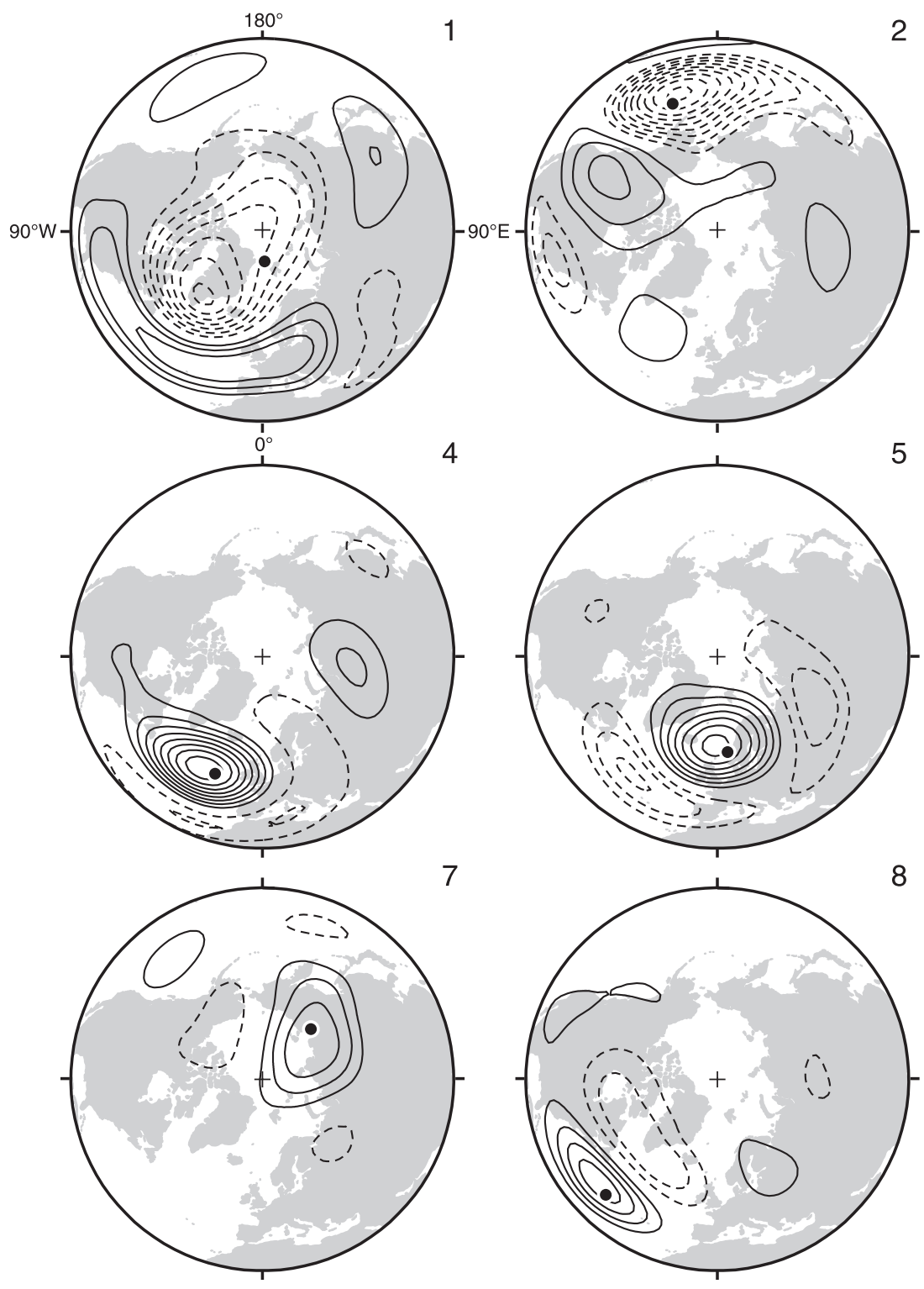

2

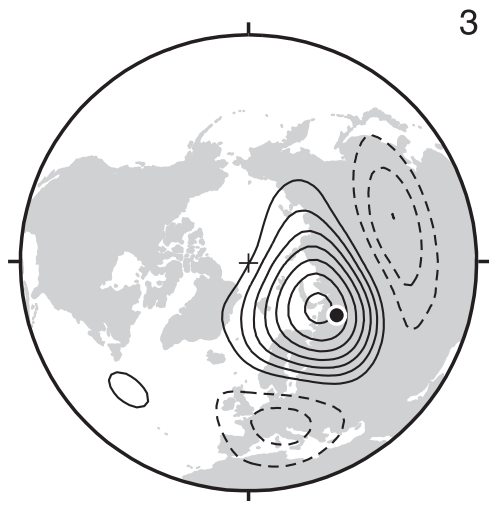

5
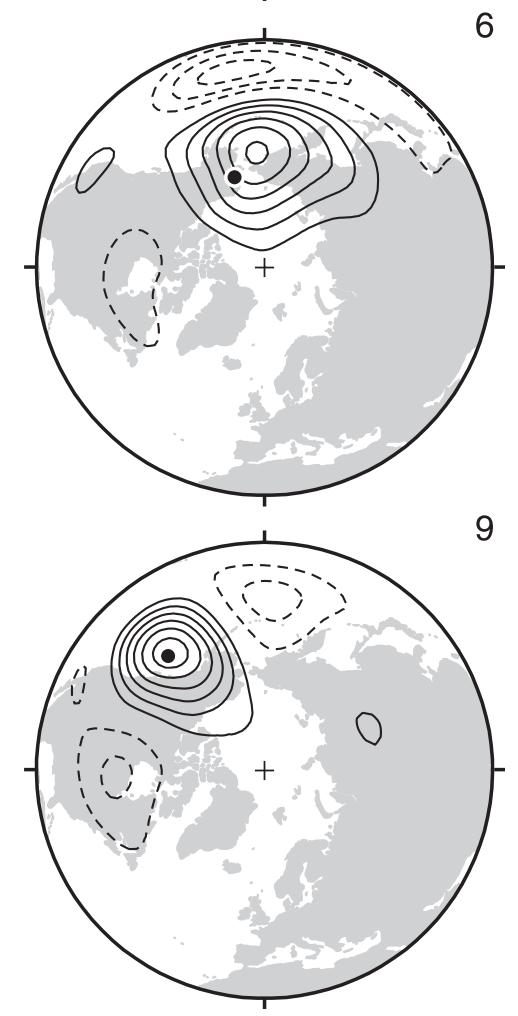

9

FIG. 4. The upper-level signature of the leading EOTs of NH wintertime SLP, formed by regressing the hemispheric field of 500-hPa geopotential height anomalies onto the respective EOT standardized expansion coefficient time series. Display is as in Fig. 2, including the SLP EOT base points, except that the contour interval is $10 \mathrm{~m}$ per standard deviation of the corresponding EOT expansion coefficient time series.

patterns and selected statistics out to nine modes. To keep the analysis compact, we will show only the EOTs, but we have verified that a similar set of patterns is recoverable using REOF analysis (Smoliak 2009). The emphasis here is not so much on producing the definitive renditions of the individual patterns as on illustrating the structural characteristics of the family of patterns.

The leading nine EOTs of NH wintertime SLP are shown in Fig. 2 and their percentage contributions to the hemispherically integrated variance of SLP $\left(20 \mathrm{hPa}^{2}\right)$ are listed in the first column of Table 1. In deference to the previous literature, we have assigned the negative polarity to the primary centers of action of wintertime EOTs 1 and 2, so that they correspond to the NAM and the PNA pattern, respectively. We have assigned a positive polarity to the primary center of action of EOTs 3-9, consistent with the sign convention in Van den Dool et al. (2000).

For reference in discussing the patterns in Fig. 2, we show in Fig. 3 that the first six of those patterns correspond closely to the leading EOFs in $120^{\circ}$ sectors of the hemisphere. The sectors are chosen so as to maximize the correspondence. Figure 5.6 in Smoliak (2013) documents the degree of similarity and the range of 
longitude over which it is observed, both of which decline with increasing EOF number.

In discussing the patterns in Fig. 2, we will also have occasion to refer to the corresponding patterns of 500-hPa height anomalies shown in Fig. 4. These patterns, obtained by regressing the monthly $500-\mathrm{hPa}$ height field onto the time-varying index of each EOT, are also mainly monopolar but they contain secondary features. In modes 1, 4, 6 , and 8 the features are arranged as north-south dipoles, whereas in modes 2,3 , and 9 they are arranged more like east-west-oriented wave trains. In all cases, the primary center is of the same polarity as the SLP center and of comparable amplitude and it lies to the west of it, albeit only slightly for all but the first and sixth modes. These properties are suggestive of a predominantly barotropic vertical structure with a weak baroclinic component.

Now we proceed to a more detailed description of the individual modes. EOTs 1-3, shown in the top row of Fig. 2, each explain $10 \%-20 \%$ of the variance of hemisphericmean SLP individually and approximately $40 \%$ collectively. As noted above, these "first tier" patterns closely resemble the leading EOFs in their respective sectors of the hemisphere. EOT1 corresponds to the NAO/NAM and EOT2 corresponds to the PNA pattern (note, in particular, the corresponding $500-\mathrm{hPa}$-height regression pattern in Fig. 4), whereas EOT3 has no clear historical precedent in the literature apart from Smoliak (2009).

EOTs 4-6, shown in the second row of Fig. 2, explain 5\%$10 \%$ of the SLP variance individually and $20 \%$ collectively. Whereas EOTs 1-3 bear a close resemblance to the leading EOFs in their respective sectors, EOTs 4-6 resemble the second EOFs shown in the second row of Fig. 3. The 500hPa-height regression pattern for EOT4, shown in Fig. 4, resembles the East Atlantic pattern of Wallace and Gutzler (1981) and a similar mode has also been recovered by in studies of jet stream and storm-track variability over the Atlantic sector by Woollings et al. (2010), Athanasiadis et al. (2010), and Wettstein and Wallace (2010). The 500-hPaheight regression pattern corresponding to EOT5 bears a strong resemblance to the upper-level signature of the socalled Scandinavian pattern (Barnston and Livezey 1987; Bueh and Nakamura 2007). EOT6 projects upon the North Pacific Oscillation (NPO; Walker and Bliss 1932; Bjerknes 1969), which has been shown to influence the occurrence of cold-air outbreaks over western North America (Rogers 1981; Hsu and Wallace 1985; Linkin and Nigam 2008).

EOTs 7-9 bear some resemblance to the third EOFs of the SLP field in their respective sectors (not shown), but the correspondence is not as close as it is for EOTs $1-6$. Individually these patterns explain from $2.5 \%$ to $5 \%$ of the variance of hemispherically integrated SLP and collectively they account for approximately $10 \%$, bringing the cumulative total to approximately $70 \%$.

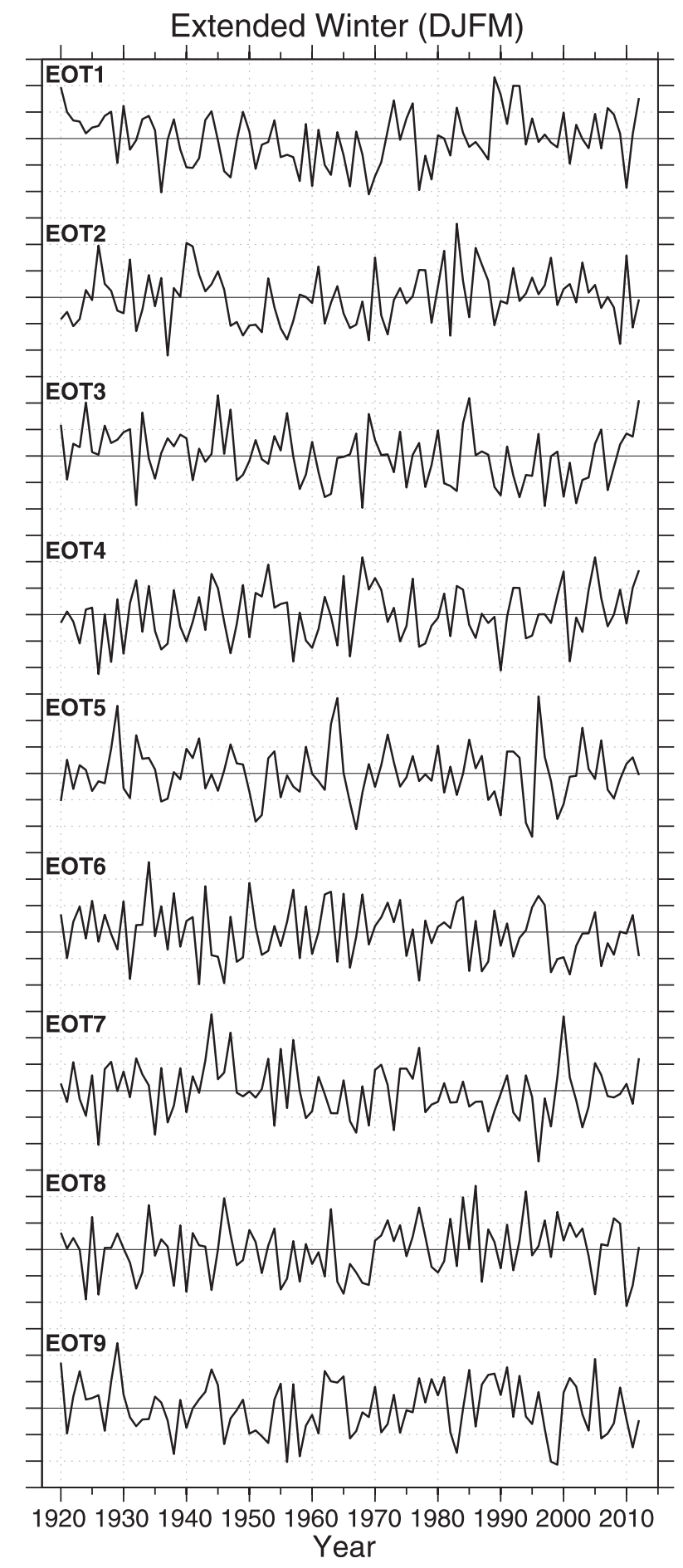

FIG. 5. Standardized seasonal-average time series based on monthly mean expansion coefficient time series corresponding to the leading nine EOTs of NH wintertime (DJFM) SLP, 1920-2012. Tick marks on the abscissa represent one standard deviation of the seasonally averaged time series. 
(a)
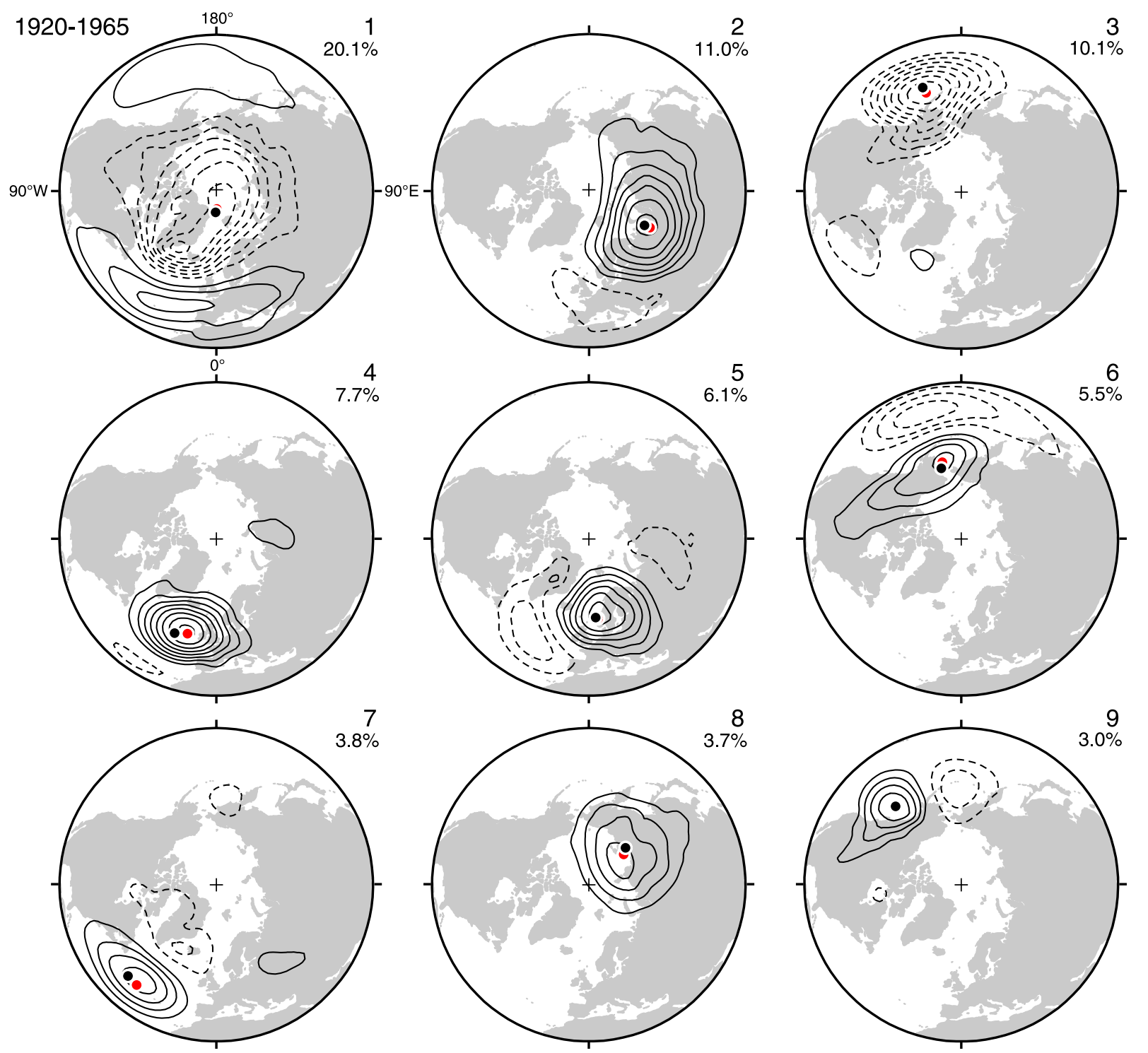

FIG. 6. EOTs based on the first and second halves of the 93-yr SLP dataset. (a) The leading nine EOTs of NH wintertime SLP, based on a 46-yr (1920-65) record of SLP anomaly fields from the 20CR. (b) The leading nine EOTs of NH wintertime SLP, based on a 47-yr (19662012) record of SLP anomaly fields from the 20CR. Contouring conventions are as in Fig. 1. EOT base points are indicated with red circles; for reference, the corresponding EOT base points from the analysis of the full 93-yr SLP dataset (Fig. 2) are reproduced with black circles. The fraction of hemispherically integrated SLP variance explained by each EOT is shown immediately below the corresponding EOT number.

\section{a. Relationship with the SAT field}

Most of the nine leading EOTs of NH wintertime SLP are associated with well-defined SAT patterns, indicated by the colored shading in Fig. 2. The fraction of hemispheric SAT (land only) variance explained by each pattern is listed in the second column of Table 1. EOTs $1-3,4-6$, and $7-9$ account for approximately $23 \%, 10 \%$, and $6 \%$ of the variance of SAT over the NH continents, respectively. Compared to their contributions to SLP variance, EOTs 3 and 6 explain disproportionally large fractions of the variance of SAT. As explained in previous studies by Wallace and Gutzler (1981) and Thompson and Wallace (2000), horizontal temperature advection and, in particular, the advection of the climatological-mean temperature field by the anomalous wind field play an important role in forcing the temperature anomalies associated with EOTs 1 and 2. In subsequent EOTs as well, southerly geostrophic wind anomalies tend to be associated with positive SAT anomalies and vice versa. 
(b)
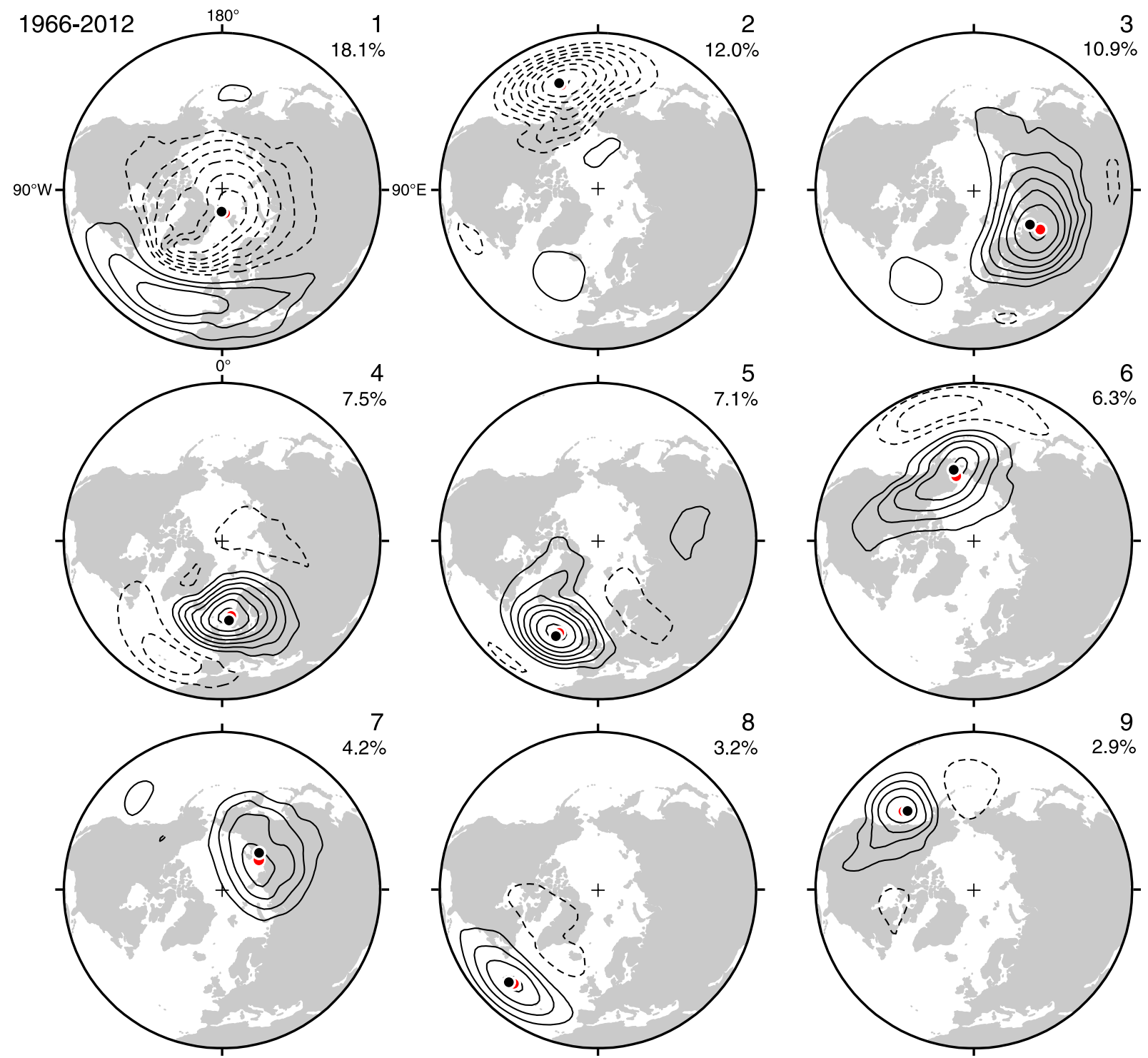

FIG. 6. (Continued)

However, from EOT3 onward, the strongest SAT anomalies appear to be associated with cold-air damming on the poleward and/or continental side of the major mountain ranges. Signatures of the Himalayas and other west-east-oriented mountain ranges of Eurasia are evident in EOTs 3, 5, and 7 and the signature of the Rockies is evident in EOTs 2 and 6.

Most of the corresponding SAT patterns are predominantly of one polarity: below-normal SAT tends to be observed in association with positive SLP monopoles and vice versa. To quantify this apparent relationship, the third column of Table 1 shows the fraction of the variance of the time series of Northern Hemispheremean SAT poleward of $20^{\circ} \mathrm{N}$ (land only) explained by the time series of each EOT. Since the predictors are mutually orthogonal, their contributions are additive. Based on the statistics in Table 1,52\% of the variance of NH-mean SAT can be explained on the basis of the "dynamical contribution" from the first nine EOTs. The corresponding percentage inferred from the method of partial least squares (PLS) regression as described in Smoliak et al. (2015) with three PLS predictors is $58 \%$. Hence, using EOTs as a basis for adjusting the NH-mean SAT time series to remove the dynamical contribution, though not optimal, appears to be nearly as effective as the methodologies used in Thompson et al. (2009), Wallace et al. (2012), and Smoliak et al. (2015) for removing the dynamically (as 
(a)

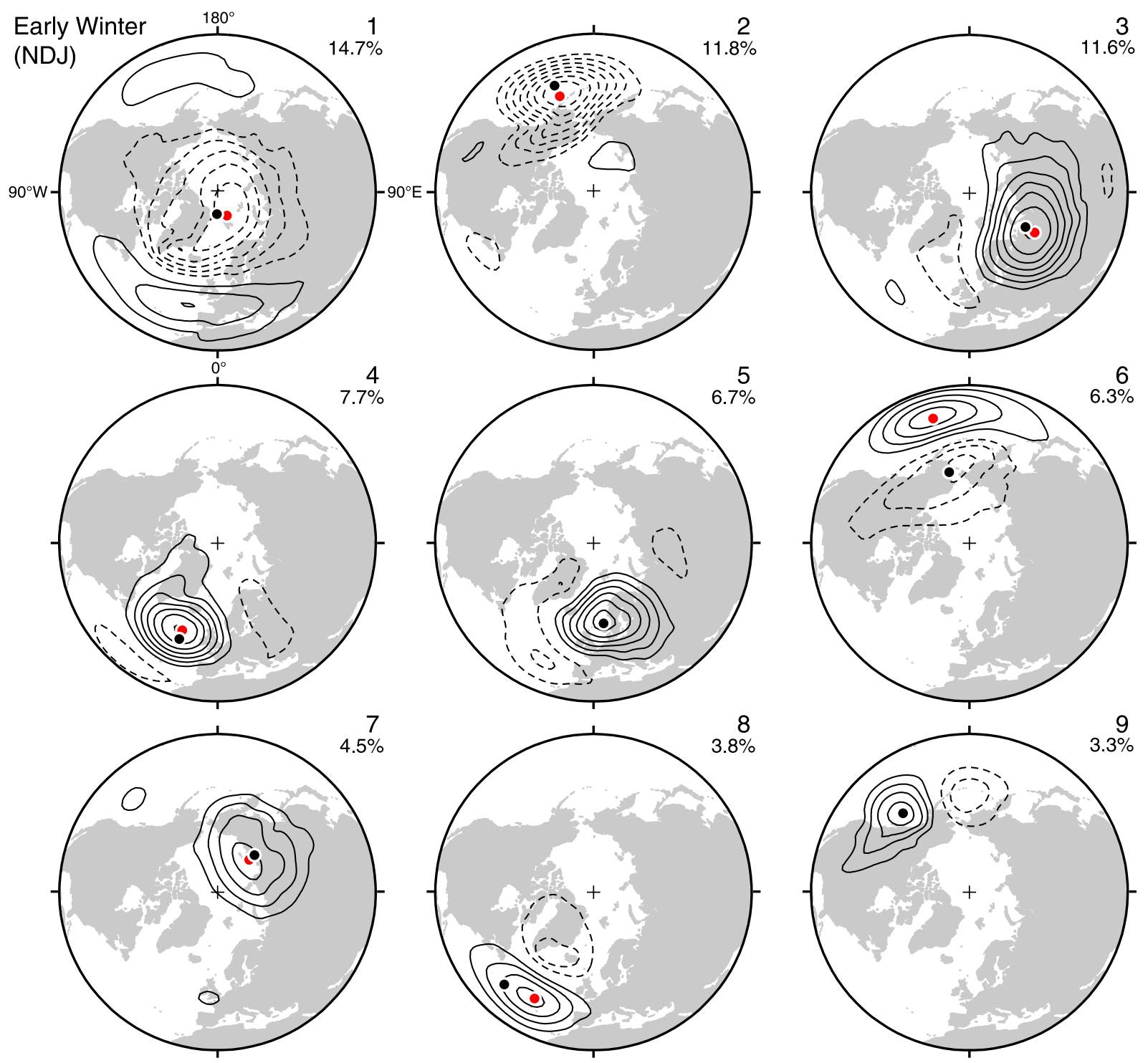

FIG. 7. EOTs based on early and late winter months from the 93-yr SLP dataset. (a) The leading nine EOTs of NH early winter (NDJ) SLP. (b) The leading nine EOTs of NH late winter (FMA) SLP. EOT base points are indicated with red circles; for reference, the corresponding EOT base points from the analysis of extended winter (DJFM) SLP data (Fig. 2) are reproduced with black circles. The fraction of hemispherically integrated SLP variance explained by each EOT is shown immediately below the corresponding EOT number.

opposed to radiatively) induced variability. Furthermore, EOTs have the advantage of revealing more transparently the anomalous circulation patterns that contribute to the dynamical adjustment.

\section{b. Trends}

Time series of standardized indices of the EOTs over the 1920-2012 period of record are shown in Fig. 5 and standardized linear trends computed from these time series are shown in the fourth column of Table 1. For reference, the $95 \%$ significance level, based on the two- sided Student's $t$ test described in Casola et al. (2009) and Thompson et al. (2015), corresponds to a standardized trend of \pm 0.72 standard deviations over the 93-yr record. By this measure, the only statistically significant trend in Table 1 is the decline in EOT3. It is notable that EOTs 5, 6 , and 7, which are analogous to EOT3 in the sense that their primary centers of action lie along the margin of the Arctic, also exhibited declines, consistent with the pattern of SLP trends documented in Fig. 5 of Smoliak et al. (2015). SLP declines over northern Eurasia and Alaska during the 1920-2010 time frame contributed to 
(b)

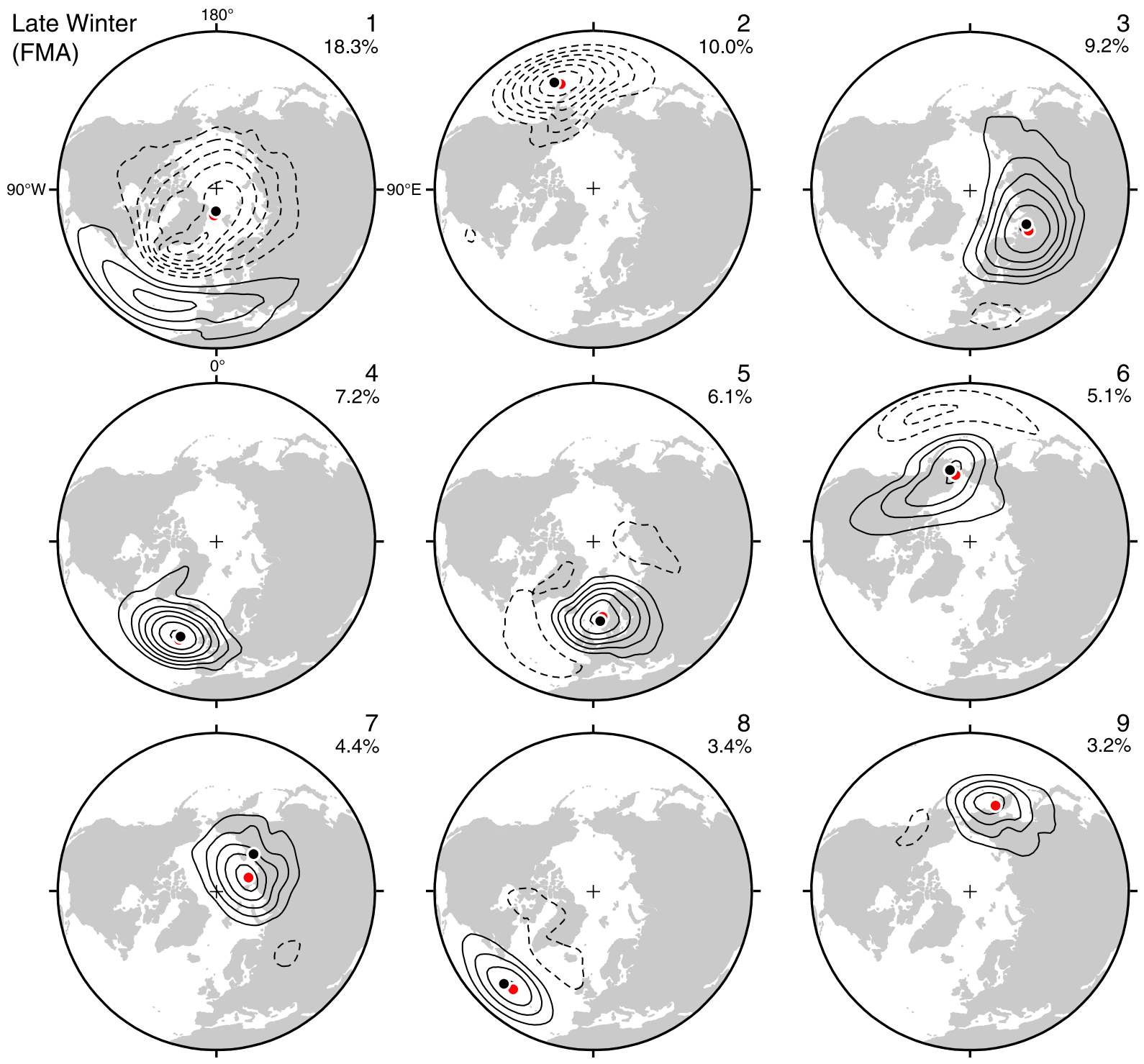

FIG. 7. (Continued)

the wintertime warming of the high-latitude $\mathrm{NH}$ continents (Wallace et al. 2012; Smoliak et al. 2015). On the other hand, it is clear from an inspection of the time series in Fig. 5 that the values of the trends are highly sensitive to the choice of end points for the reference period.

The fifth column of Table 1 shows the interannual-tointraseasonal-variance ratio (i.e., the variance of the 4-month winter seasonal means divided by the month-tomonth variance within 4-month winters) for each of the EOTs and the sixth column shows the 1-month-lag correlation. These columns are comparable to Table 1 of $\mathrm{QW}$ but based on a much longer period of record. Consistent with results of $\mathrm{QW}$, the two leading modes exhibit substantially larger values of both of the variance ratio and the 1-month-lag correlation than the modes that follow. The default value of the variance ratio for monthly values drawn from the same random normal population is $1 / 4 /(1-1 / 4)=1 / 3$. We have verified this value based on a Monte Carlo simulation and determined that for 93-yr samples the standard error is \pm 0.02 . Based on the estimates of the variance ratio in Table 1 , the interannual signal in EOTs 1 and 2 is roughly comparable in amplitude to the intraseasonal variability. The variance-weighted interannual-to-intraseasonal-variance ratio for EOTs 3-9 is 0.37 . Hence, from EOT3 onward the variance associated with the interannual variability that might conceivably be attributable to, for example, tropical SST anomalies is less than half as large as the variance associated with 


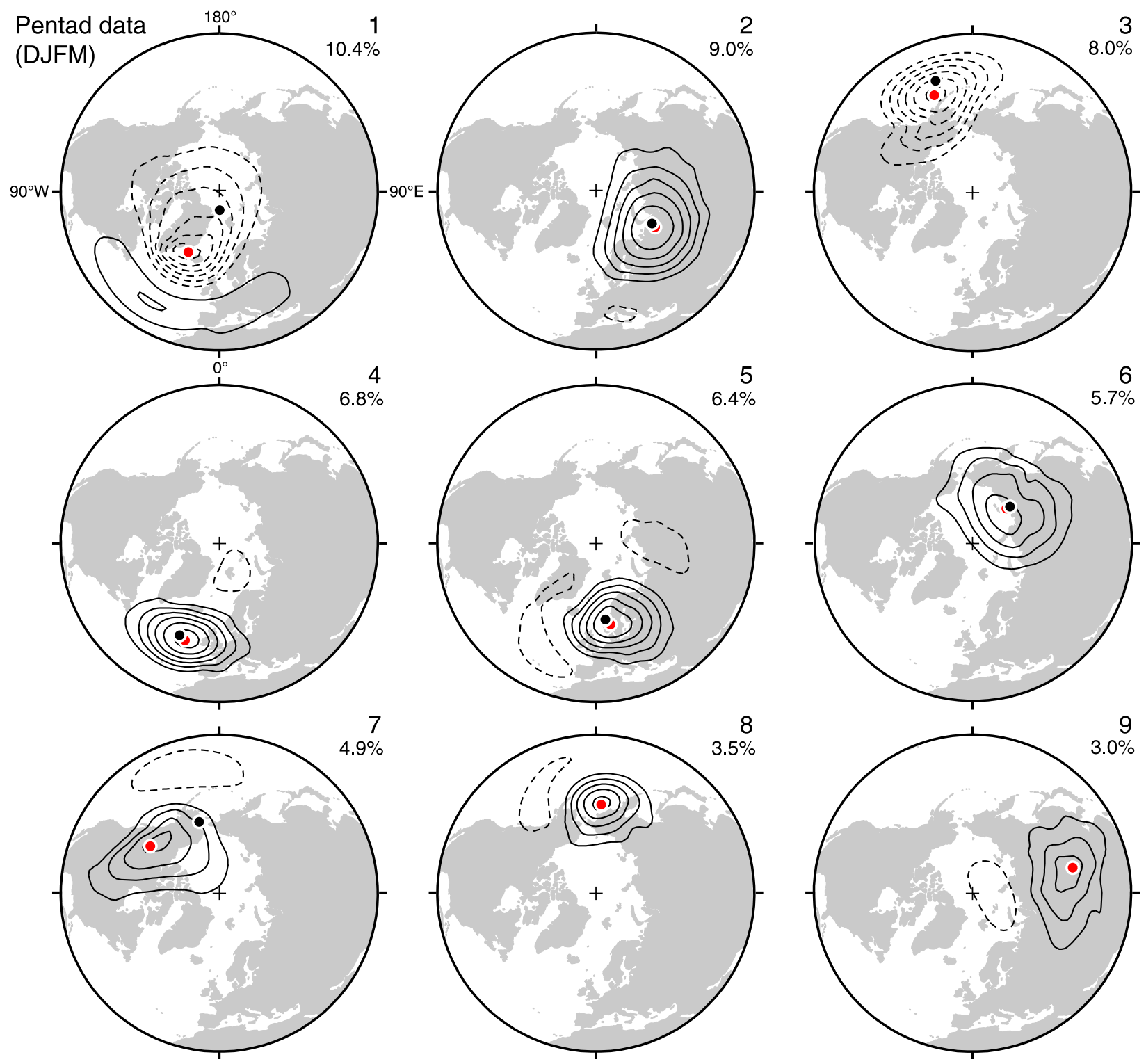

FIG. 8. The leading nine EOTs of NH wintertime SLP as in Fig. 2, but based on pentad-mean data. Contour interval is $2 \mathrm{hPa}$ per standard deviation of the corresponding expansion coefficient time series. EOT base points are indicated with red circles; for reference, the corresponding EOT base points from the analysis of monthly mean SLP data (Fig. 2) are reproduced with black circles. The fraction of hemispherically integrated SLP variance explained by each EOT is shown immediately below the corresponding EOT number.

sampling fluctuations and the possibility that it is zero cannot be ruled out at the $95 \%$ confidence level.

The 1-month-lag correlation of the monthly time series of EOTs 1-3 within individual winters is statistically significant at well above the $95 \%$ level $( \pm 0.12)$. The corresponding values for EOTs 4-9 are not statistically significant individually, though they are biased toward the positive polarity.

What sets the two leading modes apart from the others is not entirely clear. The redness of EOT1 (the NAM) may be due to the strong positive feedback associated with wave-mean flow interaction (Lorenz and Hartmann 2003). The redness of EOT2 (the PNA pattern) likely derives, at least in part, from its strong projection on the extratropical response to ENSO and ENSO-like interdecadal variability. By linearly regressing the ENSO-related variability out of the EOT2 time series using the unfiltered time series of the leading principal component of the sea surface temperature (SST) departure field in Zhang et al. (1997), the variance ratio is reduced from 0.77 to 0.55 and the lag correlation is reduced from 0.33 to 0.21 , but they 


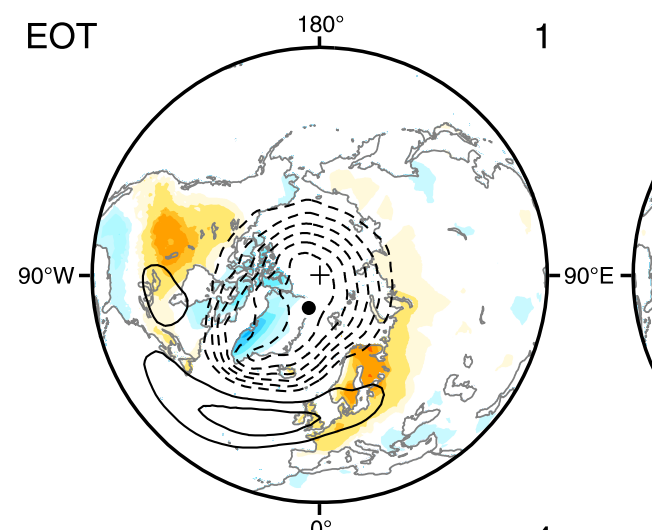

4

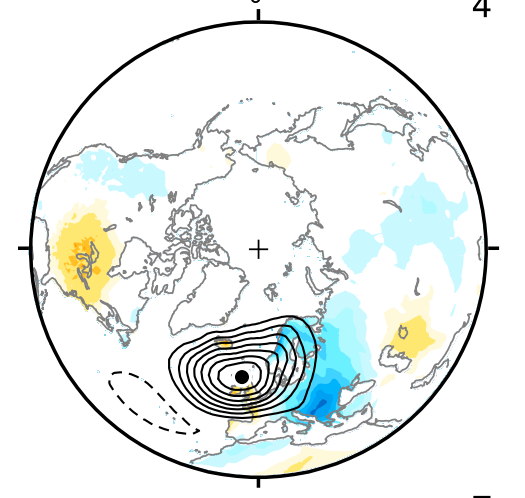

7

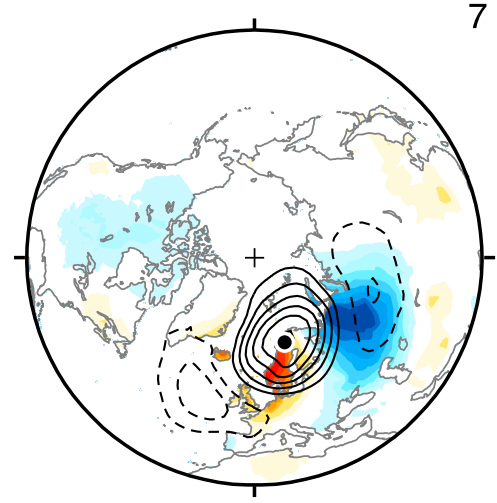

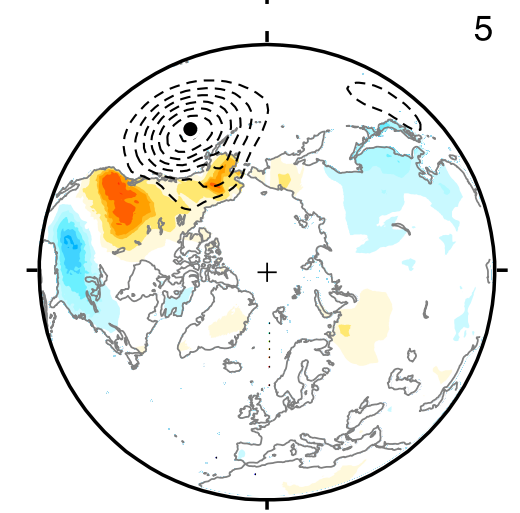

8
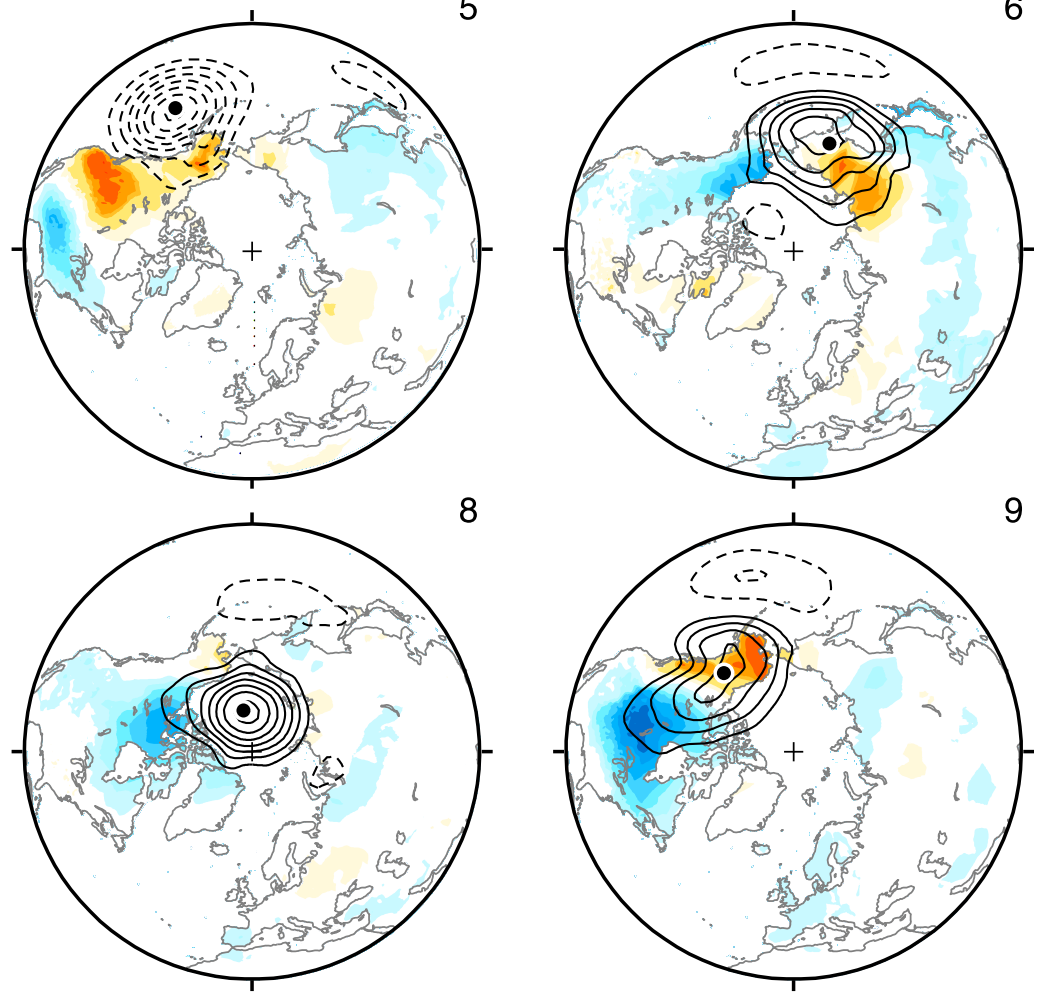

9

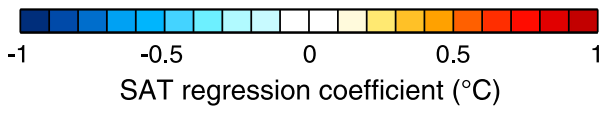

FIG. 9. The leading EOTs of NH summertime SLP, based on a 93-yr (1920-2012) record of SLP anomalies from the 20CR. Regressions of the CRU TS 3.22 SAT field onto the corresponding standardized EOT expansion coefficient time series are shown in colors. Contour interval is $0.5 \mathrm{hPa}$ per standard deviation of the corresponding expansion coefficient time series, zero contour is omitted, and negative values are contoured with dashed lines. For visualization purposes, the coefficients associated with the first and fifth patterns are multiplied by -1 .

remain conspicuously high compared to the values for EOTs 3-9.

\section{c. Robustness of the leading EOTs}

Figure 6 compares the EOTs based on the first (192065) and second (1966-2012) halves of the dataset. That the patterns in EOTs 1-9 are highly reproducible, apart from differences in ordering of modes that explain comparable amounts of variance, attests to the insensitivity of the patterns to the subtle changes in the background flow that have taken place over the past century in response to global warming and differences in the observing system. Unlike many of the patterns described in previous studies (e.g., Barnston and Livezey 1987), the wintertime EOT patterns are also insensitive to the subtle differences in the background flow between 
TABLE 2. As in Table 1, but for NH summertime (JJAS) EOT expansion coefficients.

\begin{tabular}{|c|c|c|c|c|c|c|}
\hline \multirow[b]{2}{*}{ EOT } & \multicolumn{3}{|c|}{ Variance explained } & \multirow{2}{*}{$\begin{array}{l}\text { Linear trend } \\
(1920-2012)\end{array}$} & \multirow{2}{*}{$\begin{array}{l}\text { Variance } \\
\text { ratio }\end{array}$} & \multirow{2}{*}{$\begin{array}{l}\text { 1-month-lag } \\
\text { autocorrelation }\end{array}$} \\
\hline & NH SLP & NH SAT & NHSAT & & & \\
\hline 1 & 11.9 & 1.6 & 1.5 & -0.16 & 0.51 & 0.19 \\
\hline 2 & 6.1 & 1.8 & 2.0 & -0.76 & 0.51 & 0.11 \\
\hline 3 & 5.6 & 4.8 & 0.0 & -0.23 & 0.46 & 0.09 \\
\hline 4 & 5.4 & 1.7 & 1.8 & 0.88 & 0.50 & 0.18 \\
\hline 5 & 5.2 & 1.5 & 0.6 & 0.65 & 0.31 & 0.04 \\
\hline 6 & 4.7 & 1.4 & 0.0 & -1.55 & 0.53 & 0.15 \\
\hline 7 & 4.3 & 2.6 & 0.0 & 0.10 & 0.45 & 0.14 \\
\hline 8 & 4.2 & 1.0 & 0.0 & -0.59 & 0.47 & 0.13 \\
\hline 9 & 3.4 & 2.4 & 2.2 & -0.42 & 0.42 & 0.10 \\
\hline
\end{tabular}

early winter [November-January (NDJ)] and late winter [February-April (FMA)] climatologies, apart from changes in ordering, as shown in Fig. 7. Late winter EOT9, which does not appear elsewhere in this study, resembles early winter EOT10 (not shown). Similar EOTs are also obtained when the analysis is performed on pentad-mean rather than monthly mean data, as shown in Fig. 8. The most notable distinction is that in the analysis based on pentad-mean data, two higher-order EOTs $(8$ and 9) do not have counterparts in the leading nine EOTs of monthly mean data. EOT8 and EOT9 of the pentadmean data correspond to EOT12 and EOT17 of the monthly mean data, respectively.

As an additional test of the robustness of the wintertime patterns, we recomputed them based on the EOTs of the SLP field weighted by the cosine of latitude as opposed to the square root of cosine of latitude (i.e., weighting mass rather than variance by area), as suggested by Trenberth et al. (2005). The patterns, shown in Fig. S1 of the supplemental material, are very similar to those in Fig. 2.

\section{Summertime patterns}

Figure 9 shows the NH summertime hemispheric EOT patterns in a format similar to Fig. 2 but with the SLP and SAT scales adjusted to reveal the structure of these weaker patterns. EOT1 resembles the wintertime NAM but is smaller in scale and EOTs 3, 5, and 9 bear some resemblance to their wintertime counterparts $(3,2$, and 6 , respectively). As in winter, the primary center of action of most of the patterns is situated poleward of $60^{\circ} \mathrm{N}$.

A statistical summary of the summertime modes is presented in Table 2. The SLP variance is substantially smaller during summertime than during wintertime (2.6 versus $10.7 \mathrm{hPa}^{2}$ averaged over the $\mathrm{NH}$ poleward of $20^{\circ} \mathrm{N}$ ) and it is not as strongly concentrated in the leading modes. The variance of summer SAT is also much less than that of winter SAT $\left(0.4^{\circ}\right.$ versus $\left.1.9^{\circ} \mathrm{C}^{2}\right)$ and only about half as much of it is explained by the leading nine EOTs $(19 \%$ versus $39 \%$ ). The trend in EOT2, the counterpart of wintertime EOT3, is statistically significant and the even larger trend in EOT6, which encompasses eastern Siberia and Hokkaido, is clearly evident in its time series shown in Fig. 10. The trends in some of the summertime EOTs are larger than those of their wintertime counterparts and their algebraic signs are mixed. This erratic behavior, together with the fact that the ratios of the interannual to intraseasonal variance and their 1-month-lag correlations are slightly higher than for the wintertime EOTs raises suspicions that the reanalysis data might exhibit inhomogeneities that are more prominent during summertime (Ferguson and Villarini 2014), when the dynamically induced SLP variability is much smaller. It is evident from Table 2 and from Fig. 9 (taking into account the scale of the color shading) that temporal variations in the summertime EOTs also contribute much less to the variance of the summertime NHSAT time series.

Results documenting the robustness of the summertime EOT patterns are shown in the supplemental material, comparing the two halves of the 93-year dataset (Fig. S2), early and late summer (Fig. S3), and pentadmean data (Fig. S4).

\section{Discussion}

The leading EOTs of the Northern Hemisphere SLP field poleward of $20^{\circ} \mathrm{N}$ are summarized in Fig. 11. EOTs 1 and 2 are virtually identical to the NAO/NAM and the PNA pattern, respectively. The former owes its existence to barotropic wave-mean flow interactions mainly involving the Atlantic storm track (Lorenz and Hartmann 2003) and the latter to barotropic instability of the zonally varying flow in the exit region of the Asian-Pacific jet stream (Simmons et al. 1983). EOT1 dominates the SLP variability over the Arctic and EOT2 dominates the variability over the North Pacific. EOTs 3-9 appearing in the order 8, 4, 5, 3, 7, 6, and 9 resemble links in a chain that nearly encircles the primary center 
Extended Summer (JJAS)

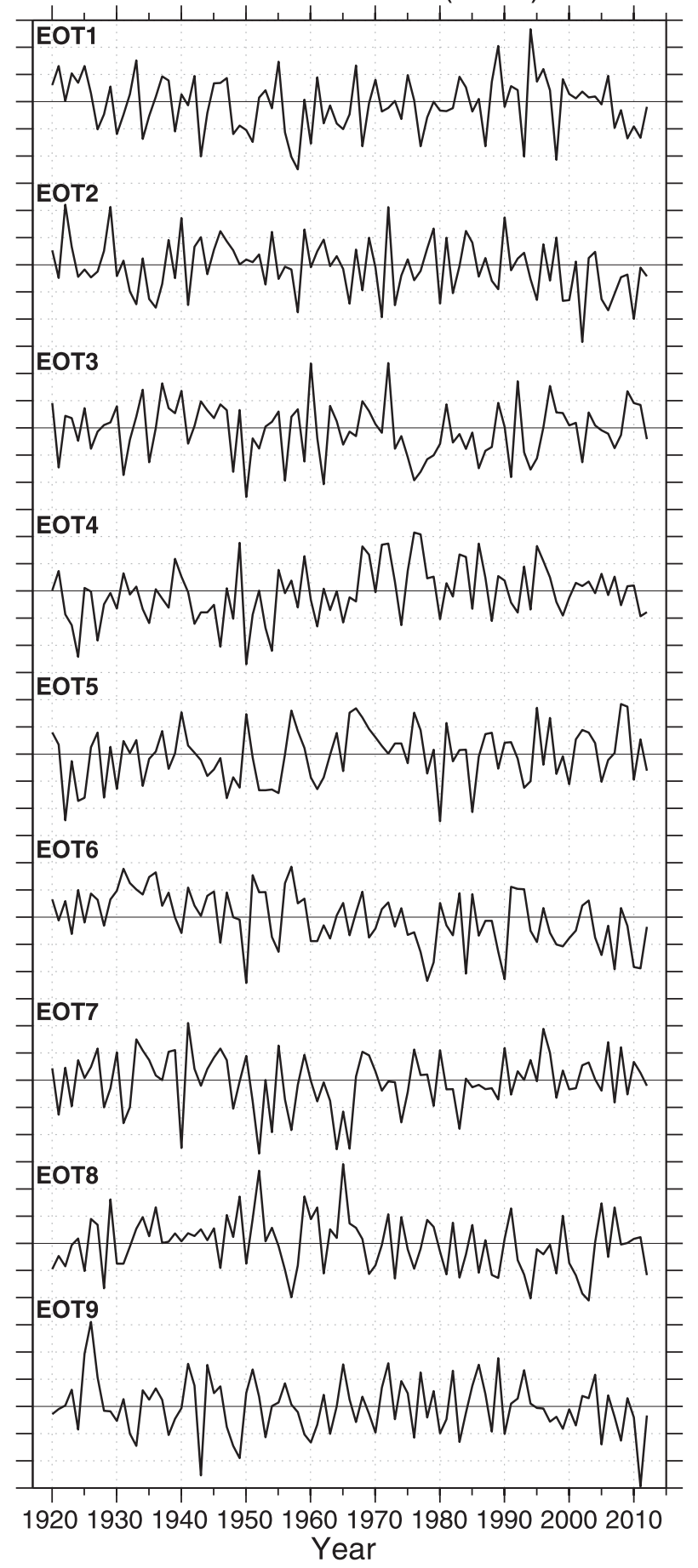

FIG. 10. Standardized seasonal-average time series based on monthly mean expansion coefficient time series corresponding to the leading nine EOTs of NH summertime (JJAS) SLP, 1920-2012. Tick marks on the abscissa represent one standard deviation of the seasonally averaged time series. of action of EOT1, with one end in the central North Atlantic and the other end in the Gulf of Alaska. The summertime EOTs shown in Fig. 11 exhibit a similar tendency to cluster around the periphery of what may be regarded as that season's annular mode or NAO. The SH patterns shown in Fig. 12 exhibit a similar tendency, especially in summertime. The same large-scale organization is also exhibited by $\mathrm{NH}$ and $\mathrm{SH}$ patterns based on pentad-mean data, shown in Figs. S5 and S6 of the supplemental material.

The salient characteristics of the family of $\mathrm{NH}$ wintertime EOFs are exemplified by EOT3, the strongest one of them, located near the midpoint of the chain. It is an SLP monopole centered along the Arctic coast, with negative SAT anomalies on its southern flank, where cold air is trapped by the Himalayas. EOT3 also modulates snowfall over a large expanse of Eurasia (Smoliak 2009, Fig. 5.4). Although the primary SLP centers of action of most of these patterns lie poleward of the most populated regions of the hemisphere, the associated SAT patterns extend deep into temperate latitudes. Each family member exhibits its own peculiar features depending on the regional land-sea geometry and orography; for example, EOTs 3 and 6 exhibit the strongest SAT patterns, and EOTs 4 and 8, which are both located over the North Atlantic, exhibit weak SAT patterns. But the family resemblance with respect to the positioning and size of the SLP monopoles is evident in all the patterns.

That the planetary-scale annular modes that emerge as EOT1 in both hemispheres and both seasons exhibit larger spatial scales than subsequent EOFs would seem to suggest that they are not merely superpositions of regional modes, as suggested by Gerber and Vallis (2005) and Kushner and Lee (2007). Presumably, the positive feedback of the baroclinic waves and the mean flow, as described in studies of Lorenz and Hartmann (2001, 2003), Vallis et al. (2004), and others plays a much more important role in these modes than in subsequent ones. The ratio of hemispheric SLP variance explained by EOTs 1 and 2 is larger in the monthly mean data than in the pentad-mean data for both hemispheres $(\sim 3: 1$ versus $\sim 2: 1$ in the $\mathrm{SH} ; \sim 2: 1$ versus $\sim 1: 1$ in the $\mathrm{NH})$. That the NAO/NAM is less prominent among the EOTs derived from the pentad-mean data shown in Fig. 8 and Fig. 54 suggests that its frequency spectrum is redder than that of subsequent modes, consistent with the prior results of Feldstein (2000) and QW, as well as the notion that it takes a few weeks for this feedback mechanism to generate a planetary-scale pattern. It would be interesting to see whether the modal structures generated by aquaplanet models and simpler models based on dynamical cores exhibit a similar frequency dependence.

It remains to be seen whether the other members of these families of EOT patterns represent genuine 


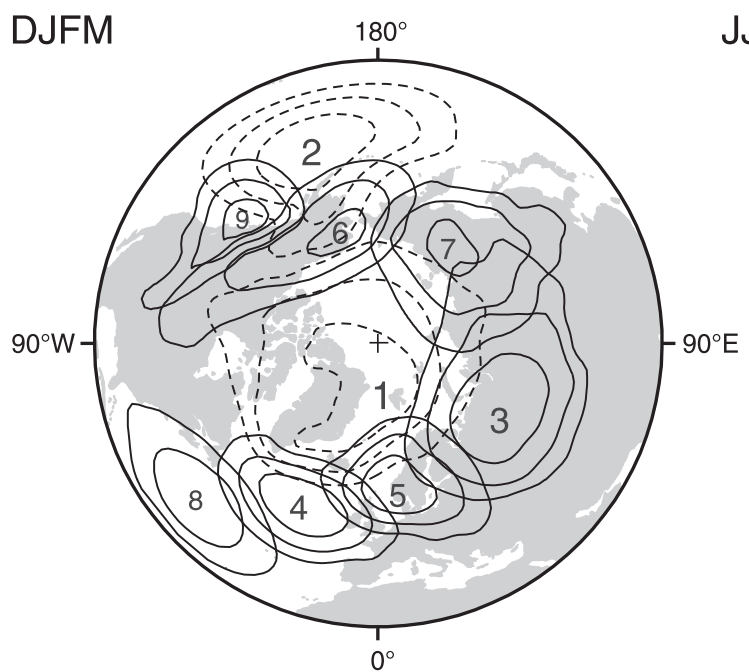

JJAS

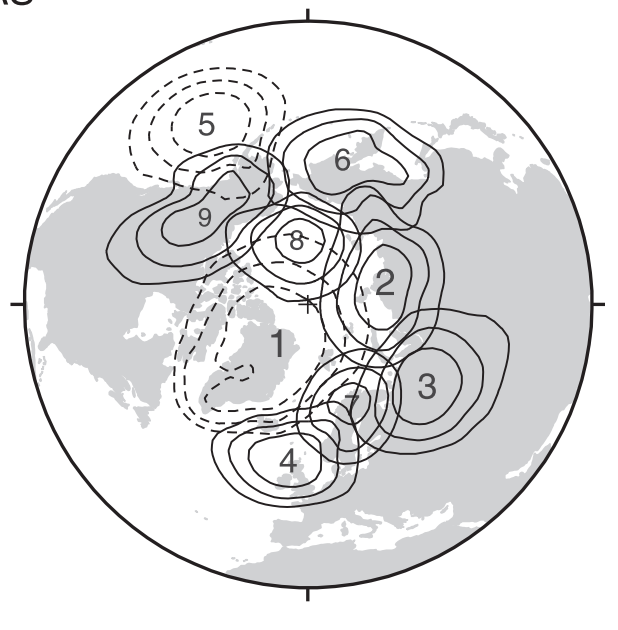

FIG. 11. Summary of the leading nine EOTs of monthly mean NH wintertime and summertime SLP shown in (left) Fig. 2 and (right) Fig. 9, displayed as correlation coefficient contours surrounding the primary center of action $( \pm 0.4$, 0.6 , and 0.8 ) between local SLP anomalies and the expansion coefficient time series of the respective EOTs.

dynamical modes of variability or whether they are mere artifacts of a modal decomposition of random low-frequency variability in the donut-shaped domain surrounding the annular mode. The remarkable robustness of the NH EOTs is evidence that mountain ranges and land-sea geometry and the existence of the PNA pattern (EOT2) and its Atlantic counterpart the EA pattern (EOT4) tend to anchor and shape the $\mathrm{NH}$ wintertime EOTs. Longitudinally dependent constraints appear to be less important in the $\mathrm{SH}$, as evidenced by the relatively stronger circular symmetry of the SH patterns in Figs. 12 and S6. Irrespective of whether the patterns represent genuine dynamical modes of variability, time variations in their amplitude and polarity (apart from those of the annular mode and the PNA) appear to be dominated by stochastic intraseasonal variability. Boundaryforced variability probably plays a secondary role, but, based on the observed interannual-to-intraseasonal-variance ratios, it is highly unlikely that it could account for more than $20 \%$ of the variance of the EOT expansion coefficient time series on the interannual time scale. In the presence of such large intraseasonal variability, detection and attribution of interdecadal (10-30-yr) trends in individual EOTs is problematical.

Issues concerning dynamical interpretation notwithstanding, for purposes such as extended-range weather prediction and diagnosis of climate impacts, it may be useful to consider a more extensive set of patterns than just the NAO/NAM and the PNA pattern. The EOTs
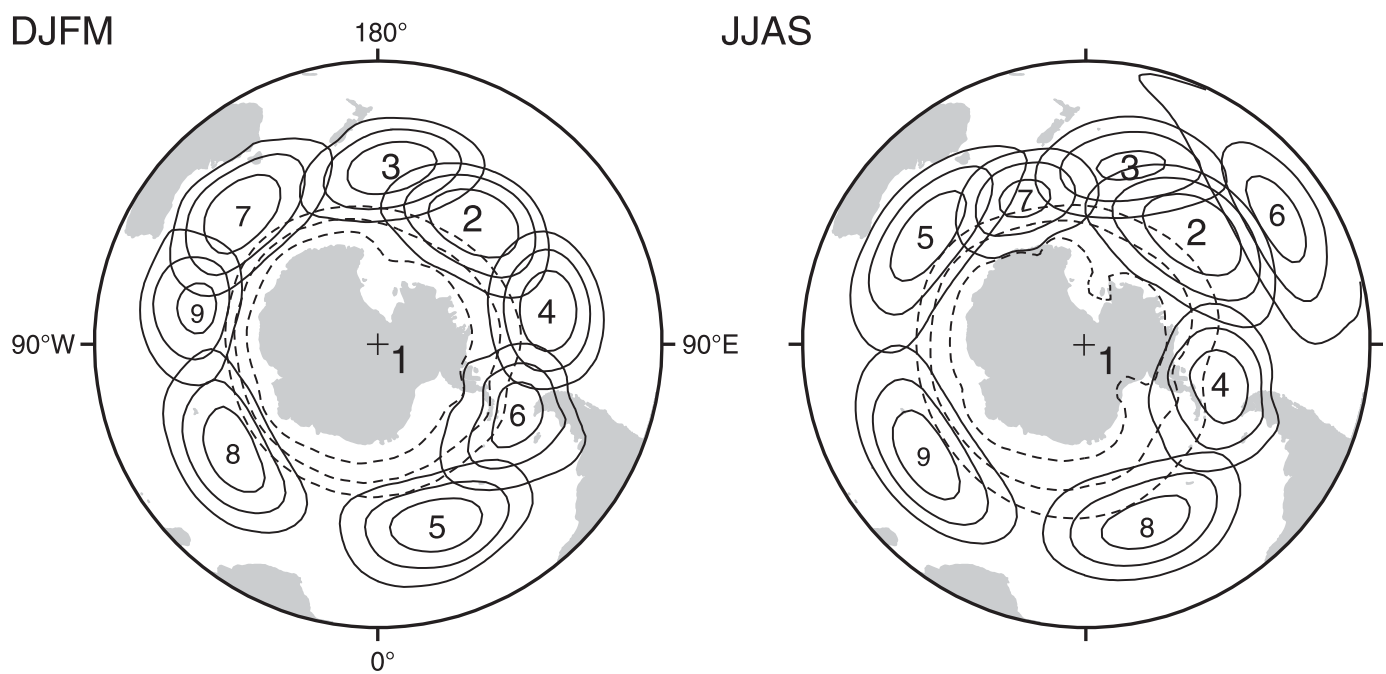

FIG. 12. As in Fig. 11, but for the SH. 
described in this study lack the pedigrees of the patterns used for these purposes (e.g., by NOAA/NCEP Climate Prediction Center), many of which date back to the catalog of Barnston and Livezey (1987, hereafter BL). Nonetheless, we believe they deserve consideration for the following reasons:

- Apart from the order in which they appear, they are remarkably robust.

- They are much less seasonally dependent than the patterns defined in BL. Some of the same patterns are even recognizable during summer and winter.

- Indices of a single set of patterns could be used to characterize month-to-month and low-frequency dayto-day variability.

- Their monopole structures in SLP are simpler and more local than the wavelike structures that characterize the dominant patterns in the geopotential height field aloft.

- Grouped as a family, they offer a systematic way of characterizing the more salient hemispheric circulation anomalies.

The ambiguity in the ranking could be obviated by identifying the modes in terms of the geographical locations of their respective primary centers of action rather than by EOT number. In particular, it would be useful to have a name for wintertime EOT3, perhaps simply the Russian (RU) pattern.

Some aspects of the patterns such as the skewness of their expansion coefficients, their possible relationship to the storm tracks, and their time-dependent behavior as manifested in lag correlation statistics have not been addressed in this paper because they require the analysis of daily data, which is beyond the scope of this paper.

Acknowledgments. The work was supported by the Climate Dynamics program office of the National Science Foundation under Grant 0812802.

\section{REFERENCES}

Ångström, A., 1935: Teleconnections of climatic changes in present time. Geogr. Ann., 17, 242-258.

Athanasiadis, P. J., J. M. Wallace, and J. J. Wettstein, 2010: Patterns of wintertime jet stream variability and their relation to the storm tracks. J. Atmos. Sci., 67, 1361-1381, doi:10.1175/2009JAS3270.1.

Barnston, A. G., and R. E. Livezey, 1987: Classification, seasonality and persistence of low-frequency atmospheric circulation patterns. Mon. Wea. Rev., 115, 1083-1126, doi:10.1175/ 1520-0493(1987)115<1083:CSAPOL > 2.0.CO;2.

Bjerknes, J., 1969: Atmospheric teleconnections from the equatorial Pacific. Mon. Wea. Rev., 97, 163-172, doi:10.1175/ 1520-0493(1969)097<0163:ATFTEP>2.3.CO;2.

Bueh, C., and H. Nakamura, 2007: Scandinavian pattern and its climate impact. Quart. J. Roy. Meteor. Soc., 133, 2117-2131, doi:10.1002/qj.173.
Casola, J. H., L. Cuo, B. Livneh, D. P. Lettenmaier, M. T. Stoelinga, P. W. Mote, and J. M. Wallace, 2009: Assessing the impacts of global warming on snowpack in the Washington Cascades. J. Climate, 22, 2758-2772, doi:10.1175/2008JCLI2612.1.

Cheng, X., and T. Dunkerton, 1995: Orthogonal rotation of spatial patterns derived from singular value decomposition analysis. J. Climate, 8, 2631-2643, doi:10.1175/1520-0442(1995)008<2631: OROSPD $>2.0 . \mathrm{CO} ; 2$.

—, G. Nitsche, and J. M. Wallace, 1995: Robustness of lowfrequency circulation patterns derived from EOF and rotated EOF analyses. J. Climate, 8, 1709-1713, doi:10.1175/ 1520-0442(1995)008<1709:ROLFCP > 2.0.CO;2.

Compo, G. P., and Coauthors, 2011: The Twentieth Century Reanalysis Project. Quart. J. Roy. Meteor. Soc., 137, 1-28, doi:10.1002/qj.776.

Defant, A., 1924: Die Schwankungen der atmospherischen zirkulation über dem Nordatlantischen Ozean im 25-jährigen zeitraum 1881-1905. Geogr. Ann., 6, 13-41.

Dommenget, D., and M. Latif, 2008: Generation of hyper climate modes. Geophys. Res. Lett., 35, L02706, doi:10.1029/2007GL031087.

Exner, F. M., 1913: Über monatliche witterunganomalien auf der nördliche erdhälfte im winter. Sitzungberichte Kais. Akad. Wiss., 122, 1165-1240.

Feldstein, S. B., 2000: The timescale, power spectra, and climate noise properties of teleconnection patterns. J. Climate, 13, 4430-4440, doi:10.1175/1520-0442(2000)013<4430:TTPSAC $>2.0$. CO;2.

Ferguson, C. R., and G. Villarini, 2014: An evaluation of the statistical homogeneity of the Twentieth Century Reanalysis. Climate Dyn., 42, 2841-2866, doi:10.1007/s00382-013-1996-1.

Gerber, E. P., and G. K. Vallis, 2005: A stochastic model for the spatial structure of annular patterns of variability and the North Atlantic Oscillation. J. Climate, 18, 2102-2118, doi:10.1175/ JCLI3337.1.

Harris, I., P. D. Jones, T. J. Osborn, and D. H. Lister, 2014: Updated high-resolution grids of monthly climatic observationsThe CRU TS3.10 dataset. Int. J. Climatol., 34, 623-642, doi:10.1002/joc.3711.

Hildebrandsson, H. H., 1897: Quelques recherches sur les centres d'action de l'atmosphère. K. Sven. Vetenskapsakad. Handl., 29 (3), 1-36.

Horel, J. D., 1981: A rotated principal component analysis of the interannual variability of the Northern Hemisphere $500 \mathrm{mb}$ height field. Mon. Wea. Rev., 109, 2080-2092, doi:10.1175/ 1520-0493(1981)109<2080:ARPCAO > 2.0.CO;2.

Hsu, H.-H., and J. M. Wallace, 1985: Vertical structure of wintertime teleconnection patterns. J. Atmos. Sci., 42, 1693-1710, doi:10.1175/1520-0469(1985)042<1693:VSOWTP>2.0.CO;2.

Hurrell, J. W., 1995: Decadal trends in the North Atlantic Oscillation: Regional temperatures and precipitation. Science, 269, 676-679, doi:10.1126/science.269.5224.676.

Kaiser, H., 1958: The varimax criterion for analytic rotation in factor analysis. Psychometrika, 23, 187-200, doi:10.1007/ BF02289233.

Kushner, P. J., and G. Lee, 2007: Resolving the regional signature of the annular modes. J. Climate, 20, 2840-2852, doi:10.1175/ JCLI4106.1.

Kushnir, Y., and J. M. Wallace, 1989: Low-frequency variability in the Northern Hemisphere winter: Geographical distribution, structure and time-scale dependence. J. Atmos. Sci., 46, 3122-3143, doi:10.1175/1520-0469(1989)046<3122:LFVITN >2.0.CO;2.

Lawrimore, J. H., M. J. Menne, B. E. Gleason, C. N. Williams, D. B. Wuertz, R. S. Vose, and J. Rennie, 2011: An overview of the Global Historical Climatology Network monthly mean 
temperature data set, version 3. J. Geophys. Res., 116, D19121, doi:10.1029/2011JD016187.

Linkin, M. E., and S. Nigam, 2008: The North Pacific Oscillationwest Pacific teleconnection pattern: Mature-phase structure and winter impacts. J. Climate, 21, 1979-1997, doi:10.1175/ 2007JCLI2048.1.

Lorenz, D. J., and D. L. Hartmann, 2001: Eddy-zonal flow feedback in the Southern Hemisphere. J. Atmos. Sci., 58, 3312-3327, doi:10.1175/1520-0469(2001)058<3312:EZFFIT>2.0.CO;2.

—, and - 2003: Eddy-zonal flow feedback in the Northern Hemisphere winter. J. Climate, 16, 1212-1227, doi:10.1175/ 1520-0442(2003)16<1212:EFFITN>2.0.CO;2.

Mestas-Nuñez, A. M., 2000: Orthogonality properties of rotated empirical modes. Int. J. Climatol., 20, 1509-1516, doi:10.1002/ 1097-0088(200010)20:12<1509::AID-JOC553>3.0.CO;2-Q.

Panagiotopoulos, F., M. Shahgedanova, and D. B. Stephenson, 2002: A review of Northern Hemisphere winter-time teleconnection patterns. J. Phys. IV Fr., 12, 27-47, doi:10.1051/ jp4:20020450.

Quadrelli, R., and J. M. Wallace, 2004: A Simplified linear framework for interpreting patterns of Northern Hemisphere wintertime climate variability. J. Climate, 17, 3728-3744, doi:10.1175/ 1520-0442(2004)017<3728:ASLFFI >2.0.CO;2.

Richman, M., 1986: Rotation of principal components. J. Climatol., 6, 293-335, doi:10.1002/joc.3370060305.

Rogers, J. C., 1981: The North Pacific Oscillation. J. Climatol., 1, 39-57, doi:10.1002/joc.3370010106.

Simmons, A. J., J. M. Wallace, and G. W. Branstator, 1983: Barotropic wave propagation and instability, and atmospheric teleconnection patterns. J. Atmos. Sci., 40, 1363-1392, doi:10.1175/ 1520-0469(1983)040<1363:BWPAIA > 2.0.CO;2.

Smoliak, B. V., 2009: A Eurasian pattern of Northern Hemisphere wintertime sea-level pressure variability. M.S. thesis, Dept. of Atmospheric Sciences, University of Washington, $116 \mathrm{pp}$.

_ 2013: Detection and attribution of surface air temperature change in the instrumental record. Ph.D. dissertation, Dept. of Atmospheric Sciences, University of Washington, $190 \mathrm{pp}$.

_ J. M. Wallace, P. Lin, and Q. Fu, 2015: Dynamical adjustment of the Northern Hemisphere surface air temperature field: Methodology and application to observations. J. Climate, 28, 1613-1629, doi:10.1175/JCLI-D-14-00111.1.

Teisserenc de Bort, L. P., 1883: Etude sur l'hiver de 1879-80 et recherches sur l'influence de la position des grands centres d'action de l'atmosphere dans les hivers anormaux. Ann. Soc. Meteor. Fr., 31, 70-79.

Thompson, D. W. J., and J. M. Wallace, 2000: Annular modes in the extratropical circulation. Part I: Month-to-month variability. J. Climate, 13, 1000-1016, doi:10.1175/1520-0442(2000)013<1000: AMITEC $>2.0 . \mathrm{CO} ; 2$. $\longrightarrow,-$ 一 P. D. Jones, and J. J. Kennedy, 2009: Identifying signatures of natural climate variability in time series of global-mean surface temperature: Methodology and insights. J. Climate, 22, 6120-6141, doi:10.1175/2009JCLI3089.1.

_ E. A. Barnes, C. Deser, W. E. Foust, and A. S. Phillips, 2015: Quantifying the role of internal climate variability in future climate trends. J. Climate, 28, 6443-6456, doi:10.1175/ JCLI-D-14-00830.1.

Trenberth, K. E., D. P. Stepaniak, and L. Smith, 2005: Interannual variability of patterns of atmospheric mass distribution. J. Climate, 18, 2812-2825, doi:10.1175/JCLI3333.1.

Vallis, G. K., E. P. Gerber, P. J. Kushner, and B. A. Cash, 2004: A mechanism and simple dynamical model of the North Atlantic Oscillation and annular modes. J. Atmos. Sci., 61, 264-280, doi:10.1175/1520-0469(2004)061<0264: AMASDM $>2.0 . \mathrm{CO} ; 2$.

Van den Dool, H., S. Saha, and Å. Johansson, 2000: Empirical orthogonal teleconnections. J. Climate, 13, 1421-1435, doi:10.1175/ 1520-0442(2000)013<1421:EOT>2.0.CO;2.

van Loon, H., and J. C. Rogers, 1978: The seesaw in winter temperatures between Greenland and northern Europe. Part I: General description. Mon. Wea. Rev., 106, 296-310, doi:10.1175/ 1520-0493(1978)106<0296:TSIWTB > 2.0.CO;2.

Walker, G. T., 1924: Correlation in seasonal variations of weather, IX: A further study of world weather. Mem. Indian Meteor. Dept., 25, 275-333.

- and E. W. Bliss, 1932: World weather V. Mem. Roy. Meteor. Soc., 4, 53-83.

Wallace, J. M., and D. Gutzler, 1981: Teleconnections in the geopotential height field during the Northern Hemisphere winter. Mon. Wea. Rev., 109, 784-812, doi:10.1175/ 1520-0493(1981)109<0784:TITGHF $>2.0$.CO;2.

_ Simulated versus observed patterns of extratropical Northern Hemisphere continents during the cold season. Proc. Natl. Acad. Sci. USA, 109, 14337-14342, doi:10.1073/ pnas.1204875109.

Wettstein, J. J., and J. M. Wallace, 2010: Observed patterns of month-to-month storm-track variability and their relationship to the background flow. J. Atmos. Sci., 67, 1420-1437, doi:10.1175/ 2009JAS3194.1.

Wilks, D. S., 2011: Statistical Methods in Atmospheric Sciences. 3rd ed. Elsevier, 676 pp.

Woollings, T., A. Hannachi, and B. Hoskins, 2010: Variability of the North Atlantic eddy-driven jet stream. Quart. J. Roy. Meteor. Soc., 136, 856-868, doi:10.1002/qj.625.

Zhang, Y., J. M. Wallace, and D. S. Battisti, 1997: ENSO-like interdecadal variability: 1900-93. J. Climate, 10, 1004-1020, doi:10.1175/1520-0442(1997)010<1004:ELIV>2.0.CO;2. 